\title{
Article
}

\section{Parametric Study of a Lunar Base Power Systems}

\author{
Marcin Kaczmarzyk *(D) and Michał Musiał (D) \\ Faculty of Civil and Environmental Engineering and Architecture, Rzeszow University of Technology, \\ ul. Poznanska 2, 35-959 Rzeszow, Poland; mmusial@prz.edu.pl \\ * Correspondence: kaczmar@prz.edu.pl; Tel.: +48-17-8651026
}

check for

updates

Citation: Kaczmarzyk, M.; Musiał, M. Parametric Study of a Lunar Base Power Systems. Energies 2021, 14, 1141. https://doi.org/10.3390/en14 041141

Academic Editor: Francesco Calise

Received: 12 January 2021

Accepted: 16 February 2021

Published: 21 February 2021

Publisher's Note: MDPI stays neutral with regard to jurisdictional claims in published maps and institutional affiliations.

Copyright: (c) 2021 by the authors. Licensee MDPI, Basel, Switzerland. This article is an open access article distributed under the terms and conditions of the Creative Commons Attribution (CC BY) license (https:// creativecommons.org/licenses/by/ $4.0 /)$.

\begin{abstract}
Due to the extreme cost of cargo transportation from Earth to the lunar surface, future lunar base subsystems are required to be rigorously optimized in terms of mass reduction. The purpose of this paper was to identify and evaluate the influence of key parameters of proposed lunar base power systems, as well as of the lunar environment on the total power system mass. Nine different power systems were studied as combinations of two power sources and three energy storage technologies. Power system architecture, total power demand of the base, its power management strategy, solar array structure type, Selenographic latitude and solar illumination conditions were nominated as the primary parameters for this study. Total power system mass calculations were performed for more than 200 combinations of these parameters, including three separate case studies. The total mass calculated for each combination included a power source, an energy storage unit, temperature control and the balance of system. For the wide range of studied parameters, hybrid power systems that combine solar and nuclear power were found to be the most advantageous solutions in terms of mass reduction.
\end{abstract}

Keywords: extraterrestrial building physics; power system; energy storage; lunar base; photovoltaics; nuclear reactor

\section{Introduction}

\subsection{Plans for a Lunar Base in the 20th and 21st Century}

The first conceptions of a manned lunar outpost date back to the late 1950s and early 1960s, when the feasibility of the Horizon and the Lunex projects were studied by the United States [1,2]. At that time a semi-permanent human presence on the Moon was also one of the main goals of the Soviet Union space program [3]. With the end of the successful American manned lunar Apollo program in 1972, a soviet robotic sample return, the Luna 24 mission, carried out in 1976, marked the end of vigorous lunar exploration in the 20th century [3,4]. Since late 1980s, subsequent United States (U.S.) administrations have presented their ambitious lunar manned exploration strategies that included establishing research bases or even in situ resources utilization (ISRU) facilities at the Moon's surface [5-8]. Starting with a successful mission of Chang'e-1 lunar orbiter in 2007 [9], the People's Republic of China consequently realizes their lunar exploration program that, to date, includes deploying and operating two lunar rovers [10,11], the first ever soft landing on the far side of the Moon [11], and conducting a successful sample return mission [12]. In 2017, American president Donald Trump announced a new national space program-Artemis, along with its goal to land the next man and the first woman on the Moon by 2024 [13-15]. The long-term purpose of Artemis is to engage commercial contractors and U.S. international partners to establish sustained human presence on the Moon, starting with the Artemis Base Camp located at the lunar south pole [14,16,17]. Most recently China presented the architecture and mission profile for their future manned lunar landings [18,19]. Many commentators consider these events of the last years as the very first steps of a new space race between two global superpowers, as well as a threshold of a new era of commercial space exploration [20-25]. 
These circumstances may actually result in the establishment of the very first lunar base before the end of the third decade of the 21st century.

\subsection{Lunar Base Power Systems}

One of the most challenging aspects of a lunar base design is its power system. Any manned extraterrestrial outpost will require electric power to operate various thermal control and life support systems to enable human habitation in a hostile space or planetary environment [26]. Electricity is also necessary to power scientific equipment and to run any ISRU operations. In case of any near-future lunar base, its power system will constitute a significant portion of its mass $[27,28]$. Considering the contemporary costs of space transportation, [29-32] total power system mass presents a subject of thorough optimization.

\subsection{Nuclear Fission Reactors}

Over the previous decades, two major power sources for a lunar base have been disputed. With solar cell technology of the 60s and 70s being highly inefficient, early concepts were based solely on nuclear reactors [1,2]. These solutions are reliable and able to work continuously for years, regardless of environmental conditions. In particular, space-rated, compact nuclear reactors are not dependent on the availability of solar radiation and thus are able to continuously supply power to a lunar base without a need for a massive, high-capacity energy storage system (ESS) [27,33-36]. Nonetheless, when using a nuclear reactor to power a manned lunar base, the issue of radiation protection must be addressed. A contemporary approach assumes maintaining safe separation distance between the reactor and any habitable infrastructure or using lunar regolith as shielding material [27].

\subsection{Photovoltaic System}

One of the first proposals of powering a Moon base only with an unaided photovoltaic (PV) system appeared in 1990s [37]. During the three decades that passed since, PV technologies have made considerable advances and today's space solar cells offer state-of-practice multijunction cells with efficiencies up to $32 \%$ [38]. Due to the lack of atmosphere, the Moon is an extraordinarily advantageous place to harness solar energy [39]. The most notable advantage of solar cells as a power source is their very high specific power (power-to-mass ratio, PMR). The space solar cells currently used have a PMR as high as $350 \mathrm{~W} / \mathrm{kg}$ [38]. When the balance of a plant is considered, the PMR of a complete PV system for a lunar surface may be reduced to the region of $130 \mathrm{~W} / \mathrm{kg}$ [27], which is still significantly more than the PMR of space-rated nuclear fission reactors (NFR), which offer approximately $5 \mathrm{~W} / \mathrm{kg}[27,36]$. Solar cells are, however, susceptible to cosmic radiation-a single strong solar proton event (SPE) may permanently reduce the energy efficiency of monocrystalline silicon solar cells by about $20-25 \%$ and the efficiency of the contemporary multijunction PV cells by about 5-10\%. At the Moon's surface, constant exposure to the galactic cosmic rays (GCR) is expected to cause $2-3 \%$ annual degradation of PV system performance [40].

The greatest limitation of any Solar-based power system at the lunar surface reveals itself due to exceptionally long lunar nights. Owing to the relatively slow rotation of the moon, an average lunar cycle (LC) also known as the synodic month, lasts 29.531 earth days [39]. It implies that the solar-powered lunar base must be equipped with an energy storage solution of considerable capacity, which would guarantee the functioning of a base for more than the two-week-long lunar night.

\subsection{Energy Storage Systems}

\subsubsection{Lithium-Ion Batteries}

The best available solution for ESS with sufficient technological readiness are Lithiumion (Li-ion) batteries. Li-ion batteries have very high round trip efficiency and more than ten years of successful space application history, which is more than sufficient to consider this technology adequate to use onboard a lunar base $[27,34,41]$. The most important 
issue with Li-ion batteries as a high-capacity ESS is their unsatisfactory specific energy (gravimetric energy density, eS) [42]. With eS of space-rated Li-ion batteries being approximately $200 \mathrm{Wh} / \mathrm{kg}$, meeting an electric power demand for even a relatively small lunar base throughout a lunar night requires many metric tons of Li-ion batteries [27,43], not to mention the additional mass of energy storage temperature control system (TCS). Considering the necessity for energy storage, the resulting total specific power of PV+Li-ion power system may be reduced to about $1 \mathrm{~W} / \mathrm{kg}$ [27].

\subsubsection{Regenerative Fuel Cells}

An alternative solution for the lunar base ESS are regenerative fuel cells (RFC). As described by Fraser 2012 [28] and demonstrated by Colozza 2020 [27], the specific energy of RFC-based ESS is power load-dependent. The RFC studied in the latter work reached specific energy between 456 and $830 \mathrm{Wh} / \mathrm{kg}$ for power loads between $0.5 \mathrm{~kW}$ and $28.03 \mathrm{~kW}$, respectively. That, even with relatively low round trip efficiency of RFCs, allowed reduction in the total PV+RFC vs PV+Li-ion power system mass by a factor of 2.4. Other authors [44] reported experimentally obtained eS values of RFC between 300 and $1000 \mathrm{Wh} / \mathrm{kg}$. The RFCbased ESS has never been used in space and, as of today, its technological readiness still remains insufficient for lunar base applications.

\subsubsection{Lithium-Sulphur Batteries}

Despite many unquestionable advantages that Li-ion batteries exhibit over older types of secondary cells, numerous branches of industry intensively investigate other technologies to increase the power density of energy storage, especially for large-scale applications. One of the most promising candidates are Lithium-Sulfur (Li-S) secondary cells, generally considered to be the successor of Li-ion technology for high energy density applications [45]. The theoretical gravimetric energy density of a Li-S cell is $\sim 2510 \mathrm{Wh} / \mathrm{kg}$, but the expected practical specific energy density is between 500 and $600 \mathrm{Wh} / \mathrm{kg}[46,47]$. That means that Li-S batteries are expected to have two to three times higher specific energy than the best performing contemporary Li-ion equivalents. The comparative study conducted by Siczek et al., 2020 [48] demonstrated that Li-S batteries cooperate with PV arrays equally well or, in some aspects, even better than Li-ion batteries. The study on Li-S batteries' capacity Recovery Effect performed by Maurer et al., 2018 [47] has shown that up to $20 \%$ of the nominal cell capacity can be recovered after an initial $80 \%$ depth of discharge. The fact that the Moon's crust is relatively abundant in sulfur [49] presents a potential for future manufacturing of Li-S cells from the lunar in-situ resources. It should be pointed out, however, that Li-S technology must yet be refined before entering the market. Today Li-S batteries exhibit limited instantaneous power capabilities, high self-discharge and relatively high-capacity decay $[45,46]$. In most cases, the lifespan of a Li-S cell is limited to few hundred cycles, especially at high discharge currents [45,50]. Fotouhi et al., 2017 [45] as well as Zhu et al., 2019 [46] reported that numerous academic and commercial facilities worldwide are focused on improving Li-S cell chemistry and construction. This brings promising perspectives that new, safe, efficient and high energy density batteries will become available for terrestrial and space applications in the near future.

\subsection{Total Power Demand}

The total power demand of a lunar facility depends mainly on its inventory and usage profile, along with the round trip efficiency of the applied energy storage system (ESS), as presented in detail by Kaczmarzyk et al., 2020 [33]. Generally, early lunar base concepts assumed relatively high power demands due to the extent of planned operations and to the relative inefficiency of technology of that time. Thanks to the declassification of some cold war documents, one may learn that the U.S. Air Force project LUNEX assumed powering of its subterranean military lunar outpost with a 300-kWe nuclear reactor [1]. Later projects utilized more matured technologies and were calculated to increasingly limited potential budgets. In their study on a lunar base thermal control system, Simonsen et al., 1988 [51] 
calculated total power demand for the studied subterranean lunar base to be circa $200 \mathrm{~kW}$. Revising their initial assumptions, the authors obtained a new power demand estimate equal to $135 \mathrm{~kW}$ [52]. Friedlander and Cole 1988 [53] estimated that a 50-100-kWe power system should be sufficient to support a semi-permanently inhabited lunar base with a closed-loop life support system, personnel transporters, construction equipment, limited science facilities and a pilot plant for lunar oxygen production. Waldron 1990 [54] stated that minimum power levels of 50-100 kW are required for life support and scienceonly activities, but power levels in excess of $1 \mathrm{MW}$ are needed to process lunar regolith to produce propellant oxygen at a useful rate. Swanson et al., 1990 [55] studied the same lunar architecture, as did Simonsen et al., 1988 [51], but assessed the total power demand of the facility as $100 \mathrm{~kW}$. Landis and Bailey 1990 [37] presented their estimation of the minimal electric power demand of an initial, solar powered lunar settlement with a biological air revitalization system to be $25 \mathrm{~kW}$. In order to determine the cooling load for a heat pumpbased temperature control system, Sridhar et al., 1996 [56] assumed the total power load of a studied lunar base to be $100 \mathrm{~kW}$. In 2002 Cohen [57] stated, that the typical concepts of baseline Lunar outposts with a long-term human presence (90 days or more) propose power levels of 12 to $30 \mathrm{~kW}$. Khan et al., 2006 [58] demonstrated a lunar base concept with an $81-\mathrm{kW}$ power requirement, including $43 \mathrm{~kW}$ for ISRU mining purposes. The most recent works present somewhat lower estimates for power requirements. Colozza 2020 [27] calculated the constant power demand for an ISRU oxygen production facility and six-personnel lunar base camp to be $25.8 \mathrm{~kW}$ and $28.05 \mathrm{~kW}$, respectively. Kaczmarzyk et al., 2020 [33] calculated their lunar base daily mean power load to vary between $6.7 \mathrm{~kW}$ at temporarily unmanned, "keep alive" mode up to $13.1 \mathrm{~kW}$ while operating at the maximum assumed capacity. It is to be observed that the analyses presented above are all case studies, each conducted for a particular lunar base concept for a fixed location on the lunar surface. Only [27] and [33] examined alternative power and energy storage systems for the studied bases, nonetheless still for single lunar locations and their resulting environmental conditions. More importantly, all of these works assume $100 \%$ relative sunshine duration which, in case of some interesting lunar locations, may be far remote from the fact.

\subsection{The Moon-A Globe of Extreme Illumination}

In 1722 Jacques Cassini demonstrated, that the axial tilt of the Moon equals $1.54^{\circ}$ and is constant in time [39,59]. With its axis of rotation almost perpendicular to the ecliptic plane, the Moon has practically no seasons but remains in a state of permanent equinox. For further considerations, let us assume the definitions of the true horizon and the local horizon according to [60], but with respect to the Moon. Let us define then the lunar astronomical day (LAD) as the time when the centre of the Sun's disc remains above the true horizon, and the lunar astronomical night (LAN) as the time when the centre of the Sun's disc remains below the true horizon. In that case, LADs are always almost exactly as long as LANs. At a specified lunar location, any seasonal changes in the Sun's paths of diurnal motion, diurnal surface temperature distributions or LAD/LAN ratios are so minute, that they are neglected in most practical applications [61,62]. For a given selenographic latitude $\phi_{\mathrm{sel}}{ }^{\circ}$ the maximum solar elevation angle (angular distance between the true horizon and the centre of the Sun's disc) $\mathrm{H}_{\text {sol }}$ may be calculated using Equation (1).

Equation (1)-Maximum solar elevation angle at the Moon's surface. The value $1.54^{\circ}$ - lunar axial tilt is added or subtracted at the summer or winter solstice, respectively.

$$
\mathrm{H}_{\text {sol }}=90-\varphi_{\text {sel }} \pm 1.54^{\circ}
$$

It is clear then that at the subpolar regions of the Moon the Sun always remain close to the true horizon, rising no more than $1.54^{\circ}$ above it. In such conditions, the Sun may remain obscured by terrain features for long periods of time, or as easily, may be continuously visible from sufficiently high mountain peaks. The existence of such regions of extreme illumination has been postulated by Beer and Mädler 1837 [63] and eventually confirmed by the observations made by lunar orbiters at the beginning of the 21st century [64-68]. 
Areas where direct solar illumination is highly limited or completely unavailable are called "permanently shadowed regions" or "craters of eternal darkness" whereas regions of exceptionally long illumination are referred as "peaks of eternal light" (PEL). In fact, permanently shadowed regions (PSR) may exist not only at the very lunar polar circle, but also at much lower latitudes, at the bottom of sufficiently deep depressions. McGovern et al., 2013 [69] reported that craters of eternal darkness may be found even at the 59th parallel and outside lunar polar circles; permanently shadowed regions constitute $13.361 \mathrm{~km}^{2}$ and $17.698 \mathrm{~km}^{2}$ of the northern and the southern hemispheres, respectively. Basic information concerning selected lunar craters with their floors at least partially hidden in permanent darkness are presented in Table 1.

Table 1. Selected LUNAR craters of eternal darkness [65].

\begin{tabular}{cccc}
\hline Name & Selenographic & Diameter $\mathbf{( k m )}$ & Depth $\mathbf{( k m )}$ \\
\hline Shackleton & $89.9^{\circ} \mathrm{S} 0.0^{\circ} \mathrm{E}$ & 21 & 4.2 \\
Shoemaker & $88.1^{\circ} \mathrm{S} 44.9^{\circ} \mathrm{E}$ & 50.9 & 2.5 \\
Erlanger & $86.94^{\circ} \mathrm{N} 28.62^{\circ} \mathrm{E}$ & 9.9 & \\
Sylvester & $82.7^{\circ} \mathrm{N} 79.6^{\circ} \mathrm{W}$ & 58 & $\mathrm{NA}$ \\
Cabeus & $84.9^{\circ} \mathrm{S} 35.5^{\circ} \mathrm{W}$ & 98 & 4 \\
Rozhdestvenskiy & $85.2^{\circ} \mathrm{N} 155.4^{\circ} \mathrm{W}$ & 177 & $\mathrm{NA}$ \\
\hline
\end{tabular}

As of today, no perfect peaks of eternal light have been positively identified. However, numerous locations were found to remain directly illuminated throughout most of a year. Examples of such locations can be found in Table 2. Presented values of relative sunshine duration are mean values for the year 2020. The values were calculated respective to the $\mathrm{LAD}$, i.e., $100 \%$ means continuous illumination throughout a lunar astronomical day, and $200 \%$ would mean that the location actually remains continuously sunlit.

Table 2. Solar illumination conditions of the selected mountain peaks at the lunar south polar regions [64].

\begin{tabular}{ccc}
\hline Location & Selenographic & Relative Sunshine Duration \\
\hline Shackleton crater rim, point A & $89.68^{\circ} \mathrm{S} 166.0^{\circ} \mathrm{W}$ & $162 \%$ \\
Shackleton crater rim, point B & $89.44^{\circ} \mathrm{S} 141.8^{\circ} \mathrm{W}$ & $164 \%$ \\
Gerlache crater rim & $88.71^{\circ} \mathrm{S} 68.7^{\circ} \mathrm{W}$ & $170 \%$ \\
Shackleton crater rim, point C & $88.79^{\circ} \mathrm{S} 124.5^{\circ} \mathrm{E}$ & $172 \%$ \\
Malapert mountain A & $86.04^{\circ} \mathrm{S} 2.7^{\circ} \mathrm{E}$ & $148 \%$ \\
Malapert mountain B & $86.00^{\circ} \mathrm{S} 2.9^{\circ} \mathrm{W}$ & $148 \%$ \\
\hline
\end{tabular}

Lunar PELs and PSRs are locations of great scientific and engineering importance. The former offer exceptionally advantageous conditions for PV power systems, while the latter may contain water ice and other frozen volatiles preserved by these cold traps [70-72]. The rim of the Shackleton crater that lies at the south pole of the Moon offers numerous PELs, while its interior remains in perpetual darkness [64,65]. This is the main reason, why the Shackleton crater is a subject of interest of both American and Chinese lunar exploration programs $[14,16,19]$.

\subsection{Aims and Objectives}

To date no study of a lunar base power system has been published that would analyze the influence of multiple technical and environmental variables on the vital parameters of the system. Unlike the case studies presented in Section 1.6, the purpose of this work was to perform a multiparametric study of a lunar base's power systems with particular focus on the influence of the wide range of site illumination conditions and power management strategies on the total power system mass. Other variables included the most important parameters of photovoltaic and nuclear power sources combined with three alternative energy storage systems. The main objective of this study was to identify the most efficient ways to reduce a lunar base power system mass and to apply these recommendations 
to select a feasible and reliable power system for three lunar outposts to enable their functioning in three completely different lunar locations and environmental conditions.

\section{Materials and Methods}

\subsection{Method}

As stated in Section 1.2, the mass of the payload to be transported into space is a critical parameter for the mission feasibility and its cost analysis. Thus, the main objective of this study was to determine and compare total masses of alternative power systems to be applied in a lunar base. Our goal was to examine the influence of selected key parameters of the base and its power system on its total mass. We nominated seven variable parameters for the evaluation:

- total power demand of the base;

- daily power load management strategy;

- $\quad$ type of applied power source;

- type of solar array structure;

- type of applied energy storage or energy buffering system;

- the base location (selenographic latitude);

- solar illumination conditions;

We therefore conducted total mass calculations for nine power system architectures for over twenty different sets of parameters. The obtained results were subjected to comparative analysis.

\subsection{General Assumptions}

We based some aspects of this analysis on the lunar base power load calculation procedure presented in the previous work of the corresponding authors-Kaczmarzyk et al., 2020 [33]. This study was performed for a lunar base of the same architecture as of the LUNARES habitat, although the architecture of the base influenced only the power demand of a base TCS, which presents a relatively small portion of the total power load. The LUNARES habitat is depicted in Figure 1. The object is located at the former military airport in Pila, Poland. It has functioned since 2017 as the first European simulated planetary base.

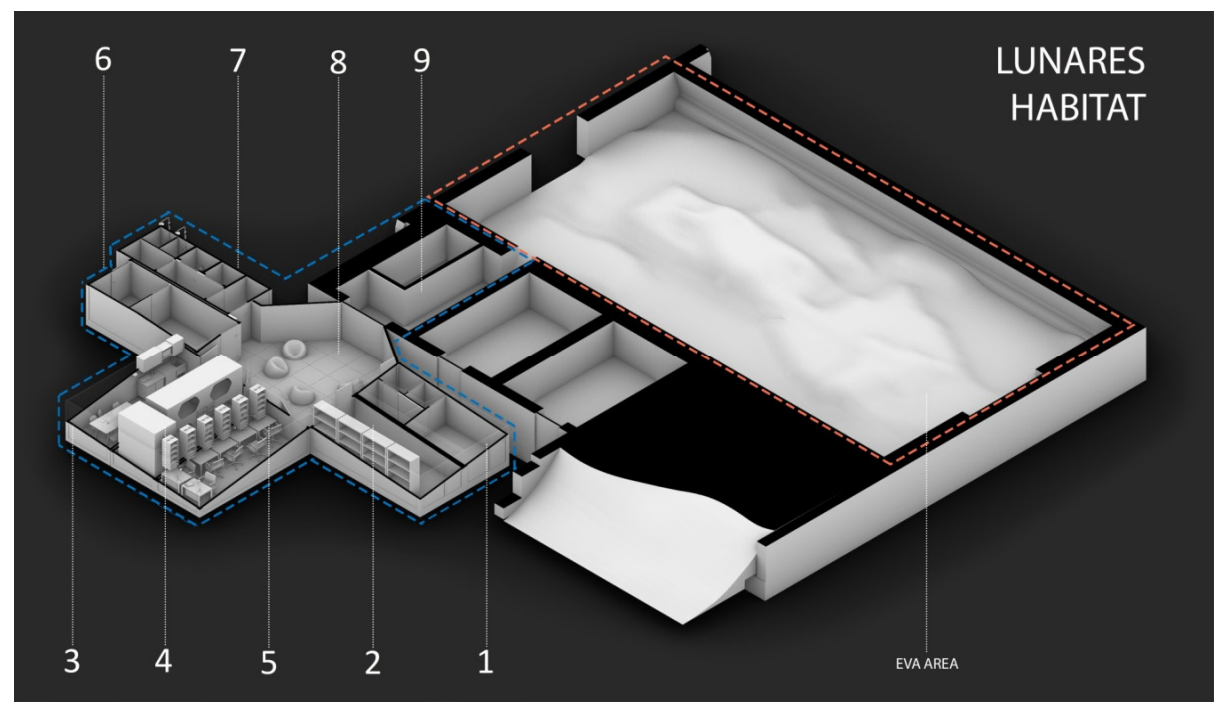

Figure 1. An axonometric projection of the LUNARES habitat three-dimensional model. Source: Leszek Orzechowski and Agata Mintus. Layout of LUNARES habitat is presented in Table 3. 
Table 3. Compartments in LUNARES habitat.

\begin{tabular}{cccc}
\hline No. & Compartment & Floor Surface Area $\mathbf{( m}^{\mathbf{2}} \mathbf{)}$ & Interior Volume $\mathbf{( m}^{\mathbf{3}} \mathbf{)}$ \\
\hline 1 & Workshop & 17.2 & 28.8 \\
2 & Storage & 13.0 & 34.4 \\
3 & Galley & 13.0 & 30.4 \\
4 & Dormitory & 19.7 & 49.2 \\
5 & Operations room & 19.7 & 49.2 \\
6 & Biolab & 8.0 & 18.3 \\
7 & Bathroom & 8.0 & 18.3 \\
8 & Atrium & 37.2 & 150.0 \\
9 & Airlock & 15.5 & 34.0 \\
& total & 151.3 & 412.6 \\
& regulated temperature: & 135.8 & 378.6 \\
\hline
\end{tabular}

Whilst performing this study, it was found to be necessary to introduce some corrections to the original assumptions made by Kaczmarzyk et al., 2020 [33]. They are as follows:

- Due to the considerable volume of the base ESS, it was necessary to move it outside the base and to equip it with individual, passive TCS consisting of multi-layer insulation (MLI), a radiator, cold plates and heat pipes. This solution is used onboard the International Space Station (ISS) [26] and was adopted by Colozza 2020 [27]. Due to this modification, the ESS located outside the actively temperature controlled interior no longer contributed to the base internal heat gain. We addressed this modification in the base cooling load calculations.

- Another modification considered the base communication system with mission control on Earth. On account of the possible polar or far side location of the base, uninterrupted visibility of Earth could no longer be guaranteed. This forced us to revisit earlier assumptions of using direct optical communication with Earth and to substitute the system with a relay Satellite. The power demand of the lunar surface to orbit communication has been identified by [27] to be about $1 \mathrm{~kW}$.

- The base equipment was re-examined and its usage adjusted to a more energy-saving power profile e.g., previously constant lighting in the common compartments was reduced to $16 \mathrm{~h} /$ day.

- The modified configuration of the original lunar base is referred to as the baseline configuration for the further analysis.

- In the baseline configuration, the lunar base daily mean electrical equipment power demand i.e., the value determined for the entire lunar cycle, $\mathrm{P}_{\text {equ.mean }}$ equals $7355 \mathrm{~W}$. In addition to these modifications, we based our study on the following assumptions:

- As the Moon has no atmosphere and most of its surface has relatively low albedo, very little diffused radiation reaches shaded areas e.g., places shaded by boulders etc. When shading accounts for relatively large portions of the lunar landscape for prolonged periods of time, it may be assumed, that night-time conditions occur there, even during lunar astronomical days (LAD). On the contrary, during lunar astronomical nights (LAN), daytime conditions may occur at the peaks of eternal light. Our calculations addressed this phenomenon by defining lunar day (LD) as a period of time when the location of the analyzed lunar base remains directly sunlit. When the location is in shade or during LANs we assume lunar night (LN). In other words, $\mathrm{LD}$ and LN are defined by the Sun's position with respect to the local horizon, not the true horizon as was the case with LAD and LAN (Section 1.7).

- In cases when nuclear reactors are used as a power source, we also assumed the use of relatively small energy storage systems, referred to as energy buffering systems (EBS), to ensure current stability and for energy buffering, should the instantaneous power demand of the base exceed the rated power of the reactor. The EBS would also 
provide additional redundancy for the power system to be used in case of reactor malfunction.

- As in the case of the ESS, the EBS will be installed outdoors and will be equipped with its own temperature control system.

- The base power systems were designed to continuously provide assumed mean power-PLD and PLN during lunar days and nights, respectively. Any differences between instantaneous and mean power demand are covered by the ESS or EBS.

- As is the case with the International Space Station (ISS) and almost every spaceship power system, the studied lunar base uses direct current (DC).

- Considering the limited amount of fissile material in the reactor core, total power system masses were calculated for 10 years of continuous lunar base operation [27,36].

- In order to maintain PV power system performance at an approximately constant level during these 10 years, the effects of solar cell degradation in the lunar environment are regularly compensated by annual deliveries of additional solar panels.

\subsection{Parameter Range and Description}

\subsubsection{The Base Location}

The most important variable that influences lunar surface thermal conditions and maximum solar elevation angle, is selenographic latitude. The study was performed for the following latitudes: $0^{\circ}, 30^{\circ}, 60^{\circ}$ and $89^{\circ}$. The hemisphere is not specified, as the solutions may be considered symmetrical with respect to the lunar equator. As mentioned, selenographic latitude determines diurnal surface temperature distribution, which is one of the factors to be used in the radiator sizing for the energy storage temperature control system (see: Section 2.3). Table 4 contains lunar surface temperatures calculated for the selected selenographic latitudes at specified moments of the lunar cycle [73].

Table 4. Lunar surface temperatures at selected selenographic latitudes and different times of day.

\begin{tabular}{ccccc}
\hline & $\mathbf{0}^{\circ}$ & $\mathbf{3 0}^{\circ}$ & $\mathbf{6 0}^{\circ}$ & $\mathbf{8 9}^{\circ}$ \\
\hline after sunrise & 130 & 130 & 130 & 130 \\
noon & 392 & 374 & 315 & 179 \\
after sunset & 145 & 144 & 140 & 133 \\
before dawn & 95 & 77 & 65 & 60 \\
\hline
\end{tabular}

\subsubsection{Solar Illumination Conditions}

In order to account for varying solar illumination at the base site and its influence on the PV system performance, the solar radiation factor $\left(\mathrm{f}_{\mathrm{SR}}\right)$ was introduced. The value of $\mathrm{f}_{\mathrm{SR}}$ represents the ratio of solar energy received by an optimally oriented surface during the lunar day (LD) to the amount of solar energy that would be received by that surface during the lunar astronomical day (LAD).Optimally oriented surface refers to a fixed plane with maximum possible solar gain. Possible values of $\mathrm{f}_{\mathrm{SR}}$ along with their representative examples are presented in Table 5.

Table 5. Possible values of solar radiation factor with their representations.

\begin{tabular}{cc}
\hline $\mathbf{f}_{\mathrm{SR}}$ & Physical Interpretation \\
\hline $0 \%$ & permanently shadowed region, eternal lunar night \\
$0 \%<\mathrm{f}_{\mathrm{SR}}<100 \%$ & partial shading during $\mathrm{LAD}$, suboptimal illumination, $\mathrm{LD}<\mathrm{LN}$ \\
$\mathrm{f}_{\mathrm{SR}} \approx 100 \%$ & most of the lunar surface, $\mathrm{LD} \approx \mathrm{LN}$ \\
$\mathrm{f}_{\mathrm{SR}}=100 \%$ & no shading during $\mathrm{LAD}, \mathrm{LD}=\mathrm{LN}$ \\
$100 \%<\mathrm{f}_{\mathrm{SR}}<200 \%$ & subpolar mountain peak, $\mathrm{LD}>\mathrm{LN}$ \\
$160 \% \leq \mathrm{f}_{\mathrm{SR}}<200 \%$ & location commonly considered as a peak of eternal light \\
$\mathrm{f}_{\mathrm{SR}}=200 \%$ & perfect peak of eternal light \\
\hline
\end{tabular}


This study was performed for the following $\mathrm{f}_{\mathrm{SR}}$ values: $25 \%, 50 \%, 75 \%, 100 \%, 125 \%$, $150 \%, 175 \%$ and $195 \%$. $f_{S R}$ values exceeding $100 \%$ were assumed only for the lunar polar location $\left(89^{\circ}\right)$ where these illumination conditions may actually be found. It was assumed that LD and LN durations are constant. As presented by $[64,66]$ the validity of this assumption must be individually verified for a specified site.

Calculations of the lunar base external heat loads for a complete lunar cycle (nighttime heat losses and daytime solar gains) required knowledge of LD and LN durations. For the purpose of determining these two durations, a simplifying assumption was made that, for a specified location, the value of $\mathrm{f}_{\mathrm{SR}}$ is similar to the LD/LAD ratio. In that case $t_{\mathrm{LD}}$ and $t_{\mathrm{LN}}$ may be calculated using Equations (2) and (3), respectively.

Equation (2)-Length of a lunar day

$$
\mathrm{t}_{\mathrm{LD}}=\left(\frac{\mathrm{t}_{\mathrm{LC}} \cdot 24}{2}\right) \cdot \mathrm{f}_{\mathrm{SR}}[\mathrm{h}]
$$

Equation (3) - Length of a lunar night

$$
\mathrm{t}_{\mathrm{LN}}=\left(\frac{\mathrm{t}_{\mathrm{LC}} \cdot 24}{2}\right) \cdot\left(200 \%-\mathrm{f}_{\mathrm{SR}}\right)[\mathrm{h}]
$$

where:

$\mathrm{t}_{\mathrm{LD}}$-length of a lunar day $(\mathrm{h})$;

$t_{\mathrm{LN}}$-length of a lunar night $(\mathrm{h})$;

$t_{\mathrm{LC}}$-length of a lunar cycle (synodic month), $\mathrm{t}_{\mathrm{LC}}=29.531$ Earth days.

It is to be observed that this assumption may not be precise, as the solar irradiance on a fixed surface is not constant throughout daytime. This is, however, as good an approximation as can be made without precise data concerning local topography and a very sensitive astrometric model of the lunar orbit. On the other hand, any uncertainties introduced by this assumption will only directly affect the external heat loads of the base. The results of the case study performed for the very same architecture as studied here [33] shows that the external heat loads, even at the equatorial regions of the Moon, have a relatively minor impact on the total power demand of the base. We estimated that the potential error resulting from our assumption cannot be more than $\sim 3 \%$ of the total power demand of the base, and only for the baseline configuration at $0^{\circ}$ latitude. The relative error will diminish with increasing latitude and total power demand.

\subsubsection{Daily Power Load Management Strategy}

To some extent, the total mass of the base power system may be controlled by utilizing various power load management strategies. In order to save ESS mass and simultaneously utilize solar energy more efficiently, it is possible to reschedule some activities (along with their power loads) from lunar nights to lunar days. We examined the potential of this strategy by identifying the combined power demand of these lunar base systems and devices that are indispensable for base operations, especially during lunar nights. These were temperature control and life support systems, communication, internal monitoring, lighting, biolab equipment and the crew members' personal devices [33]. These combined power loads are referred to as the minimum base equipment power loads $\mathrm{P}_{\text {equ.0 }}$ equal to $6744 \mathrm{~W}$.

As a quantitative representation of power load management strategies, we introduced the power adjustment coefficient $C_{P A}$, which may take a value between 0 and 1 . The former value represents no base equipment usage rescheduling - in that case LD and LN base equipment power loads would be equal. In the opposite case, for $\mathrm{C}_{\mathrm{PA}}=1$, all non-vital power loads are rescheduled from LN to LD and the respective power loads are then calculated; the daily mean value remains unchanged. As is presented in detail in [33], the LUNARES base functioned according to Earth-based circadian rhythm, with utter disregard to the lunar diurnal cycle. Its power management strategy did not consider any power demand optimization so the power adjustment coefficient for the baseline configuration 
was assumed to be zero. In our analysis the $C_{\text {PA }}$ parameter was assumed to take following values: $0,0.33,0.66$ and 1 . Considering any potential enhancements of the base operations e.g., installing additional base equipment, supporting surface vehicles or powering ISRU operations, another parameter was introduced, allowing for convenient control of any additional power loads in our lunar base power system model. This parameter is the power increase coefficient $\mathrm{C}_{\mathrm{PI}}$ - it may take any positive value and its unit change increases the base power load by $10 \mathrm{~kW}$. It was assumed, however, that $90 \%$ of this additional power load is expended outside the base, so only the remaining $10 \%$ contributes to the base internal heat gains. In our analysis, the CPI parameter was assumed to take the value of 0,2 and 4 . The base equipment power loads for the lunar nights and lunar days were calculated using Equations (4) and (5), respectively.

Equation (4)-The base equipment lunar nighttime power load

$$
\mathrm{P}_{\text {equ.LN }}=\left(\mathrm{P}_{\text {equ.mean }}+10,000 \cdot \mathrm{C}_{\mathrm{pi}}\right) \cdot\left(1-\mathrm{C}_{\mathrm{pa}}\right)+\mathrm{C}_{\text {pa }} \cdot \mathrm{P}_{\text {equ. } 0}[\mathrm{~W}]
$$

Equation (5)-The base equipment lunar daytime power load

$$
\mathrm{P}_{\text {equ.LD }}=\frac{\left(\left(\left(\mathrm{P}_{\text {equ.mean }}+10,000 \cdot \mathrm{C}_{\mathrm{pi}}\right) \cdot\left(\mathrm{t}_{\mathrm{ld}}-\mathrm{t}_{\mathrm{ln}}\right)\right)-\left(\mathrm{P}_{\text {equ.LN }} \cdot \mathrm{t}_{\mathrm{ln}}\right)\right)}{\mathrm{t}_{\mathrm{ld}}}[\mathrm{W}]
$$

where:

$\mathrm{P}_{\text {equ.mean }}$ - the baseline configuration daily mean electrical equipment power demand (W);

$P_{\text {equ.LN }}$-lunar night-time base equipment power load;

$\mathrm{P}_{\text {equ.LD }}$-lunar daytime base equipment power load;

$\mathrm{P}_{\text {equ.0 }}$ - minimum base equipment power load (W);

$t_{\mathrm{LN}}$ - Length of a lunar night $(\mathrm{H})$;

$t_{\mathrm{LD}}$-Length of a lunar day $(\mathrm{H})$;

$\mathrm{C}_{\mathrm{PA}}$ - power adjustment coefficient;

$\mathrm{C}_{\mathrm{PI}}$ - power increase coefficient.

Based on these equipment power loads, the corresponding values of internal heat loads $Q_{\text {int,LD }}$ and $Q_{\text {int,LN }}$ were established. This aspect of the calculation was elaborated upon in detail by Kaczmarzyk et al., 2020 [33]. The next step was to determine external heat loads i.e., lunar daytime solar gains $\mathrm{Q}_{\mathrm{ext}, \mathrm{LD}}$ and lunar night-time heat losses $\mathrm{Q}_{\mathrm{ext}, \mathrm{LN}}$. These were obtained according to Simonsen et al., [52]. As soon as all the internal and external heat loads were known, power demand for LD and LN of the base TCS were calculated according to [33]. Finally, the lunar base total power demands $P_{L D}$ and $P_{L N}$ were calculated using Equations (6) and (7).

$$
\begin{aligned}
& \mathrm{P}_{\mathrm{LD}}=\mathrm{P}_{\text {equ.LD }}+\mathrm{P}_{\mathrm{TCS} . \mathrm{LD}}[\mathrm{W}] \\
& \mathrm{P}_{\mathrm{LN}}=\mathrm{P}_{\text {equ.LN }}+\mathrm{P}_{\mathrm{TCS} . \mathrm{LN}}[\mathrm{W}]
\end{aligned}
$$

where: $\mathrm{P}_{\mathrm{LD}}$ and $\mathrm{P}_{\mathrm{LN}}$ are the lunar base total power demands for lunar days and lunar nights, respectively; $\mathrm{P}_{\mathrm{TCS} . \mathrm{LDD}}$ and $\mathrm{P}_{\mathrm{TCS} . \mathrm{LN}}$ are the lunar base temperature control system power demands for lunar days and lunar nights, respectively.

\subsubsection{Power Sources}

Three main power source configurations were studied in our analysis:

- Photovoltaic array (PVA);

- Nuclear fission reactor (NFR);

- Hybrid power system (PVA+NFR).

The first configuration uses a PV array to cover lunar daytime base power demand and to produce excess energy to be stored for lunar night-time operations. During the lunar 
night the base is powered by its energy storage system (ESS). The required rated power of the PV array $\mathrm{P}_{\mathrm{PV}}$ was calculated using Equation (8):

$$
\mathrm{P}_{\mathrm{PV}}=\mathrm{P}_{\mathrm{equ} . \mathrm{LN}}+\left(\frac{\mathrm{E}_{\mathrm{LN}}}{\mathrm{t}_{\mathrm{LD}} \cdot \eta_{\mathrm{reg}}}\right)[\mathrm{W}]
$$

where:

$\mathrm{E}_{\mathrm{LN}}$-energy to be stored in the base ESS (Wh); $\eta_{\text {reg }}$-regenerative cycle energy efficiency of the base TCS.

Based on the $P_{\mathrm{PV}}$, the PV array surface area $\mathrm{A}_{\mathrm{PV}}$ was calculated according to Equation (9):

$$
\mathrm{A}_{\mathrm{PV}}=\left(\frac{\mathrm{P}_{\mathrm{PV}}}{\mathrm{TSI} \cdot \mathrm{C}_{\mathrm{ST}} \cdot \eta_{\mathrm{SC}} \cdot \mathrm{f}_{\mathrm{SA}} \cdot \eta_{\mathrm{env}}}\right)[\mathrm{W}]
$$

where:

TSI-total solar irradiance at the Moon's surface, equal to $1360 \mathrm{~W} / \mathrm{m}^{2}$ according to [39]; $\eta_{\mathrm{SC}}-$ nominal energy efficiency of the solar cells. $\eta_{\mathrm{SC}}=32 \%$ was assumed for the quadruple multijunction space solar cells, according to the manufacturer's specifications [38];

$\eta_{\text {env }}$ - mean expected environmental efficiency of the solar cells at the Moon's surface, due to the exposure to the local temperatures and cosmic radiation environment; for the selected cells $\eta_{\text {env }}=80 \%$ was assumed according to [40];

$\mathrm{f}_{\mathrm{SA}}$ - solar array fill factor (ratio of the solar cell area to the array area), $\mathrm{f}_{\mathrm{SA}}=89 \%$ [27];

$\mathrm{C}_{\mathrm{ST}}$ - the Sun tracking coefficient; its meaning is explained below and the values presented in Table 6.

\begin{tabular}{|c|c|c|}
\hline Array Type & $\begin{array}{c}\text { Absorbed Solar Energy } \\
\left(\mathrm{kWh} / \mathrm{m}^{2} / \mathrm{LD}\right)\end{array}$ & $\begin{array}{c}\mathrm{C}_{\text {ST }} \text { Sun Tracking } \\
\text { Coefficient }\end{array}$ \\
\hline Dual axis tracker & 1695.39 & $100 \%$ \\
\hline Optimally tilted single axis tracker & 1695.14 & $99.99 \%$ \\
\hline Optimally tilted fixed mount & 1049.66 & $61.91 \%$ \\
\hline
\end{tabular}

Table 6. Solar energy absorbed per unit surface by various types of solar arrays.

One of the parameters we intended to study in this paper was the orientation of the PV panels during the lunar day. Common practice for lunar PV systems is to use a fixed mount for the solar panels and to orient the array toward the equator with its tilt angle equal to the site latitude $[27,28,37,39]$. This orientation is considered optimal as it guarantees the highest insolation for fixed PV panels. As the Moon may be assumed to have no seasons, a fixed solar array orientation retains its mean effectiveness throughout the whole year. It is, however, subjected to the hourly changes in its output power due to changing solar incidence angle. This problem may be minimized by applying solar trackers, that orient the array towards the Sun. As presented by Kaczmarzyk et al., 2018 [39] thanks to the lack of the lunar atmosphere (always optical air mass AM0) applying a dual-axis solar tracker would have increased the amount of energy received by the solar array by $59 \%$ compared with the most optimally oriented fixed array. For the purpose of this study, we therefore introduced the Sun tracking coefficient which represents the ratio of the solar energy absorbed during the lunar astronomical day by the unit surface of the selected type of solar array to the same amount of energy absorbed by a dual-axis solar tracking array. In order to obtain the necessary data, we utilized the lunar engineering astrometric model developed by Kaczmarzyk et al., 2018 [39]. To account for the reduced light absorption at large incidence angles, the astrometric model was enhanced by incorporating Schlick's approximation formula for the specular reflection coefficient [74]:

$$
\mathrm{R}_{\theta}=\mathrm{R}_{0}+\left(1-\mathrm{R}_{0}\right) \cdot(1-\cos (\theta))^{5}
$$


where:

$\mathrm{R}_{\theta}$ - is the specular reflection coefficient as a function of the angle of incidence; $\theta$ - the angle of incidence;

$R_{0}$-is the minimal reflection coefficient i.e., for $\theta=0^{\circ}$. We assumed $R_{0}=0.025$ for a very wide spectral range [75].

The calculations were conducted in Matlab 2019a. The results are presented in Table 6. The Results are latitude-independent as the Moon has no atmosphere.

It is to be observed that, due to very small axial tilt of the Moon, the difference between the performance of single axis and dual axis trackers is almost imperceptible. It is clear that using more complicated and heavier dual axis trackers is ineffectual at the Moon's surface. In that case, only the fixed mount and single axis tracking solar arrays were considered in this study. Obtaining the $A_{P V}$ value enables the calculation of the mass of the PV array $\mathrm{M}_{\mathrm{PVA}}$. It consists of two components, according to Equation (11):

$$
\mathrm{M}_{\mathrm{PVA}}=\mathrm{M}_{\mathrm{PVP}}+\mathrm{M}_{\mathrm{PVS}}
$$

where the mass of PV panels (sometimes referred to as the PV blanket) $M_{P V P}$ and the mass of the array structure $M_{P V S}$ are to be calculated using Equations (12) and (13) respectively:

$$
\begin{aligned}
& \mathrm{M}_{\mathrm{PVP}}=\mathrm{A}_{\mathrm{PV}} \cdot \rho_{\mathrm{PVP}} \\
& \mathrm{M}_{\mathrm{PVS}}=\mathrm{A}_{\mathrm{PV}} \cdot \rho_{\mathrm{PVS}}
\end{aligned}
$$

where $\rho_{\text {PVP }}$ is the areal density of the PV blanket $\mathrm{kg} / \mathrm{m}^{2}$. Based on the manufacturer specification [76], $\rho_{P V P}=1.20 \mathrm{~kg} / \mathrm{m}^{2}$ was assumed $\rho_{P V S}$ to be the specific mass of the array structure $\mathrm{kg} / \mathrm{m}^{2}$. For the fixed mount we assumed $\rho_{P V S}=0.55 \mathrm{~kg} / \mathrm{m}^{2}$ for a carbon fiber reinforced structure described by Duchek et al., 2018 [77]. Note the fact, that the assumed value is about five times less than terrestrial, stainless steel fixed mounts [78]. This is possible mostly due to low lunar gravity and lack of wind or snow loads. Obtaining $\rho_{\text {PVS }}$ for Moon-designed single axis tracking arrays was more problematic, because no such structures exist yet [79]. Analyzing the differences in $\rho_{P V S}$ for terrestrial equivalents of these two array structure types $[78,80,81]$, one may assume that single axis tracking arrays are to be at least four times heavier per unit surface than fixed solutions. Comparing this observation with the upper limit of specific power defined by the National Aeronautics and Space Administration (NASA) for the solar arrays to be developed for their lunar missions [79], we assumed $\rho_{\text {PVS }}$ for a single axis tracking solar array structure equal to $2.5 \mathrm{~kg} / \mathrm{m}^{2}$. When considering a fixed mount for the $89^{\circ}$ latitude location with $\mathrm{f}_{\mathrm{SR}}>100 \%$, a double solar array surface was assumed in order to enable utilization of the sunlight coming from the polar direction. In that case, $\rho_{P V S}=0.85 \mathrm{~kg} / \mathrm{m}^{2}$ for the double-sided fixed mount was assumed.

Since our study encompasses a 10-year period of base operations, PV cells' degradation in the lunar environment must be accounted for. We assumed annual deliveries of additional PV panels to counteract the PV system performance degradation. According to [40], at the Moon's surface, state-of-the-art space solar cells will experience steady efficiency loss, about 3\% per year. In this case, keeping the PV system at its initial rated power for 10 years will require an additional 30\% of the initial PV array mass $M_{\text {PVA. }}$.

The last component of the PV system to be included in its mass calculation is the balance of system i.e., array wiring, a transmission line and a breaker box. In our calcula-

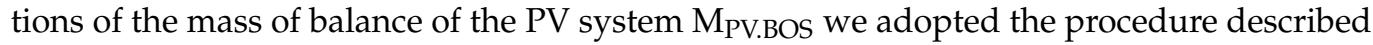
in detail by Colozza 2020 [27]. The energy storage system with all of its components is considered as a separate subsystem and its sizing and mass calculation procedure are described in Section 2.3.5. 


\begin{abstract}
Nuclear Fission Reactor
The second variant of the lunar base power source is based on utilizing a nuclear fission reactor to supply electric energy to the base. The most recent developments in the field of nuclear power for space applications are the American Kilopower project. The purpose of the project is to develop a new class of safe, efficient and reliable compact nuclear reactors with rated electrical power ranging between $1 \mathrm{~kW}$ and $10 \mathrm{~kW}$. The very first Kilopower Reactor Using Stirling Technology (KRUSTY) was successfully tested in 2019, as reported by McClure 2020 [36]. This study assumes using KRUSTY reactors to power a lunar base. The most important features of KRUSTY are presented in Table 7.
\end{abstract}

Table 7. Kilopower Reactor Using Stirling Technology (KRUSTY) reactor specifications.

\begin{tabular}{ccc}
\hline Parameter & 1-kWe Reactor & 10-kWe Reactor \\
\hline Nuclear fuel & 93 percent enriched solid cast U-235 Mo alloy \\
Design life & $>10$ years & $>10$ years \\
Advanced Stirling engine efficiency & $23 \%$ & $23 \%$ \\
Reactor thermal power output & $4.3 \mathrm{~kW}$ & $43 \mathrm{~kW}$ \\
Electrical output power & $1 \mathrm{~kW}$ & $10 \mathrm{~kW}$ \\
Output power voltage & $120 \mathrm{~V} \mathrm{DC}$ & $120 \mathrm{~V}$ DC \\
Dose rate at 100 m distance & $26.3 \mathrm{REM} /$ year & $657.5 \mathrm{REM} /$ year \\
Distance for 5 rem/year dose rate & $230 \mathrm{~m}$ & $1150 \mathrm{~m}$ \\
Total mass & $406 \mathrm{~kg}$ & $1545 \mathrm{~kg}$ \\
Parameter & $1-\mathrm{kWe} \mathrm{reactor}$ & $10-\mathrm{kWe} \mathrm{reactor}$ \\
Nuclear fuel & 93 percent enriched solid cast U-235 Mo alloy
\end{tabular}

The very first step in calculating the NFR system mass was to establish its power load. The base crew radiation protection requires location of the reactor a safe distance away from any manned infrastructure. In most cases, the distance is considerable and the associated transmission power losses must be addressed in the calculations, according to Equation (14):

$$
\mathrm{P}_{\mathrm{NFR}}=\mathrm{PBL} \cdot \mathrm{P}_{\mathrm{TL}}[\mathrm{W}]
$$

where PBL is the power demand of the lunar base, it should be assumed to be the larger value from PLD and PLN. PTL is the transmission wire power loss. Because this value may be precisely calculated only when the whole system is sized, at first its value must be based on an initial guess. After the whole system sizing is complete, the PTL must be calculated and fitted by iteration.

Comparing the masses of $1-\mathrm{kW}$ and $10-\mathrm{kW}$ reactors (Table 7 ), it is clear that the reactor mass cannot be linearly scaled below $1 \mathrm{~kW}$ of electric power. The mass of certain components cannot be reduced below a specified threshold [35,36]. It is, however, possible to scale the reactor between its two working versions. We assumed, that it will be possible to produce customized versions of KRUSTY with rated electric power within the 1-10 kW range. Based on the data provided by $[27,36]$ we determined the KRUSTY mass scaling coefficient $C_{R S}$ presented in Table 7 . It is to be observed that this coefficient is appropriate only for KRUSTY reactors between $1 \mathrm{~kW}$ and $10 \mathrm{~kW}$ of electric power. Having the rated power of a reactor assembly (PNFR), one may calculate the required number of $10 \mathrm{~kW}$ reactors $\mathrm{n}_{10 \mathrm{kWr}} \mathrm{using}$ the Equation (15):

$$
\mathrm{n}_{10 \mathrm{kWr}}=\frac{\mathrm{P}_{\mathrm{NFR}}}{10,000}
$$

The result of Equation (15) should be rounded down to a whole number. Now it is possible to calculate the number of the customized reactors using Equation (16):

$$
\mathrm{n}_{\mathrm{CPr}}=\frac{\mathrm{P}_{\mathrm{BL}}}{10,000}-\mathrm{n}_{10 \mathrm{kWr}}
$$


The result of Equation (16) has to be rounded up to a whole number; $\mathrm{n}_{\mathrm{CPr}}$ will be either 0 or 1 . If a customized-power reactor is used $\left(n_{\mathrm{CPr}}=1\right)$, its rated power should be calculated according to Equation (17):

$$
\mathrm{P}_{\mathrm{CP}}=\mathrm{P}_{\mathrm{BL}}-\mathrm{n}_{10 \mathrm{kWr}} \cdot 10,000[\mathrm{~W}]
$$

The result of Equation (17) must be rounded up to the whole multiple of 1000; the lowest possible rated electric power of KRUSTY is $1000 \mathrm{~W}$. The mass of a customized-power reactor $\mathrm{M}_{\mathrm{CPr}}$ is to be calculated using Equation (18):

$$
\mathrm{M}_{\mathrm{CPr}}=\mathrm{M}_{1 \mathrm{kWr}}+\mathrm{C}_{\mathrm{RS}} \cdot\left(P_{\mathrm{CR}}-1000\right)[\mathrm{kg}]
$$

When the number of reactors and their electric output power are known, it is possible to calculate the radiation dose rate at a100-m distance from the reactor assembly H100 using Equation (19):

$$
\mathrm{H}_{100}=\mathrm{n}_{10 \mathrm{kWr}} \cdot 657.5+\left(26.3+\left(\mathrm{P}_{\mathrm{CR}}-1000\right) \cdot \frac{(657.5-26.3)}{9000}\right)\left[\frac{\mathrm{REM}}{\mathrm{year}}\right]
$$

where 26.3 and 657.5 are dose rates in REM/year at the 100-m distance from 1-kW and 10kW KRUSTYs, respectively (Table 7). It was assumed, that the astronauts will be protected from the ionizing radiation emitted by the reactor assembly, so that their whole-body total effective dose equivalent $\mathrm{H}_{\max }$ is no more than $5 \mathrm{REM}$ /year [82]. Due to the fact that dose rates from different sources are additive and the dose rate is inversely proportional to the square of the distance from the source of radiation, we calculate the safe distance of the base from the reactor assembly $\mathrm{L}_{\mathrm{RA}}$ according to Equation (20):

$$
\mathrm{L}_{\mathrm{RA}}=\sqrt{\left(\left(\frac{\mathrm{H}_{100}}{\mathrm{H}_{\max }}\right) \cdot 100^{2}\right)}[\mathrm{m}]
$$

where 100 is the distance $m$ at which 26.3 and 657.5 REM/year dose rates are taken from $1-\mathrm{kW}$ and 10-kW KRUSTYs, respectively. The mass of the voltage converters and of the transmission line, along with transmission power loss $\mathrm{P}_{\mathrm{TL}}$ were calculated according to the procedure presented in [27]. Additionally, we optimized the transmission line wire diameter in order to obtain the lowest possible system mass. An energy buffering system with all of its components is considered as a separate subsystem and its sizing and mass calculation procedures are described in Section 2.3.5.

\section{Hybrid Power System}

The third option for a lunar base power source is the hybrid configuration that assumes using a PV system during the lunar day and a nuclear fission reactor during the lunar nights. This solution allows utilization of solar energy during the LD and assurance of powering the base during LN without a need for a massive, high-capacity energy storage system with its temperature control system. Both the PV and NFR systems in the hybrid configuration must be sized in accordance with the base power demand assumed for their respective parts of the lunar cycle. With the minor changes, PV and NFR systems are to be sized exactly as previously described. The only changes consider both systems rated power assumptions. In case of the PV system, its rated power for hybrid configuration $\mathrm{P}_{\mathrm{PV}}$ (Equation (8)) is reduced to the form: $\mathrm{P}_{\mathrm{PV}}=\mathrm{P}_{\mathrm{LD}}$. Similarly, when calculating rated power of the NFR system (Equation (14)), the base power load $\mathrm{P}_{\mathrm{BL}}=\mathrm{P}_{\mathrm{NL}}$. The energy buffering system with all of its components is considered as a separate subsystem and its sizing and mass calculation procedure are described in Section 2.3.5. 


\subsubsection{Energy Storage and Energy Buffering Systems}

Energy Storage System

An energy storage system (ESS) is a vital part of a solar-powered lunar base power system. Being recharged throughout the lunar day, the ESS function is to provide electric energy to the base during more than two-week-long lunar nights. The energy that needs to be stored in the ESS depends on its discharge cycle energy efficiency $\eta_{\text {dis }}$ as presented in Equation (21):

$$
\mathrm{E}_{\mathrm{LN}}=\mathrm{P}_{\mathrm{LN}} \cdot \frac{\mathrm{t}_{\mathrm{LN}}}{\eta_{\mathrm{dis}}}[\mathrm{Wh}]
$$

In this paper, three variants of ESS were considered: Lithium-ion (Li-ion) and LithiumSulfur (Li-S) batteries and regenerative fuel cells (RFC). The most important parameters of these ESS are presented in Table 8.

Table 8. Notable properties of the studied energy storage systems.

\begin{tabular}{cccc}
\hline ESS Type: & Li-Ion & Li-S & RFC \\
\hline regenerative cycle energy efficiency $\eta_{\text {reg }}$ & $99 \%$ & $99 \%$ & $85 \%$ \\
discharge cycle energy efficiency $\eta_{\text {dis }}$ & $99 \%$ & $99 \%$ & $65 \%$ \\
round trip energy efficiency $\eta_{\mathrm{RT}}$ & $98 \%$ & $98 \%$ & $55 \%$ \\
specific energy es $(\mathrm{Wh} / \mathrm{kg})$ & 200 & 550 & \\
specific power $\mathrm{P}_{\mathrm{MR}}(\mathrm{W} / \mathrm{kg})$ & 300 & 1000 & $300-1000$ \\
assumed depth of discharge DOD & $80 \%$ & $90 \%$ & $90 \%$ \\
ESS type: & $\mathrm{Li}-\mathrm{ion}$ & $\mathrm{Li}-\mathrm{S}$ & $\mathrm{RFC}$ \\
regenerative cycle energy efficiency $\eta_{\text {reg }}$ & $99 \%$ & $99 \%$ & $85 \%$ \\
discharge cycle energy efficiency $\eta_{\text {dis }}$ & $99 \%$ & $99 \%$ & $65 \%$ \\
\hline
\end{tabular}

In the case of both types of batteries, energy efficiency of the discharge cycle as well as their specific power are discharge-rate dependent. In general, the lower the discharge rate, the higher $\eta_{\text {dis }}$ value may be obtained $[27,41,83]$. The values presented in Table 8 refer to a relatively slow, continuous discharge throughout the lunar night. As demonstrated by Mallon et al., 2017 [84] the depth of discharge (DOD) has a very strong effect on Li-ion batteries' cycle life. For Earth orbit satellites, where long life cycles $(>30,000$ cycles) are expected [85], ensuring reliability and safety requires the DOD of Li-ion batteries to be limited to about $40 \%$ [41]. In lunar conditions, however, during 10 years of operation the batteries will experience 123 cycles only, so DOD rates as high as $80 \%$ are fully acceptable. Deep discharges are reported not to have significant effects on Li-S batteries [47]; nonetheless it was decided to leave a $10 \%$ capacity safety margin for these batteries. The RFCs can theoretically use all of the stored reactants but in practice it is to be expected that some of the water, hydrogen and oxygen will always remain in the lines and tanks, so the $10 \%$ margin was assumed here as well. Specific power and specific energy of the RFCs are, to some extent, proportional to the operating power of the system $[27,28,44]$, but these parameters had no direct influence on the applied RFC sizing process. The procedure to calculate the ESS mass depends on the type of the system. In case of the two types of batteries, the mass of batteries may be calculated according to Equation (22).

$$
\mathrm{M}_{\mathrm{B}}=\frac{\mathrm{E}_{\mathrm{LN}}}{\mathrm{e}_{\mathrm{S}} \cdot \mathrm{DOD}}[\mathrm{kg}]
$$

Besides the batteries themselves, battery-based ESS includes also the battery charge controller. We calculated its mass $\mathrm{M}_{\mathrm{BCC}}$ as presented in [27].The total mass of the batterybased energy storage system $\mathrm{M}_{\mathrm{ESS}, \mathrm{B}}$ was therefore calculated as Equation (23).

$$
\mathrm{M}_{\mathrm{ESS}, \mathrm{B}}=\mathrm{M}_{\mathrm{B}}+\mathrm{M}_{\mathrm{BCC}}[\mathrm{kg}]
$$

Sizing the RFC-based ESS is a more complicated process, which requires calculating the mass of the reactants as well as their tanks, electrolyzer and fuel cell stack. The entire 
procedure has been thoroughly described by Colozza 2020 [27] and we found it unproductive to elaborate it here.

\section{Energy Buffering System}

As described in Section 2.3.5, the energy buffering system (EBS) is a type of relatively low-capacity energy storage, that serves mostly for power regulatory purposes. In our study, we considered using the EBS in NFR and hybrid systems, as these lack the highcapacity ESS typical for PV-only power systems. According to our assumptions, the EBS must be able to deliver $130 \%$ of the maximum power load and to have sufficient capacity to provide, in case of emergency, minimum base equipment power load $\mathrm{P}_{\text {equ. } 0}$ for $24 \mathrm{~h}$ continuously. That means that there are two conditions according to which the EBS is to be sized. The first one is the output power of the batteries. Meeting this condition requires batteries' mass to be no less than that calculated using Equation (24):

$$
\mathrm{M}_{\mathrm{EBS} . \mathrm{B}, 1}=\frac{\left(1.3 \cdot \max \left(\begin{array}{c}
\mathrm{P}_{\mathrm{LD}} \\
\mathrm{P}_{\mathrm{LN}}
\end{array}\right)\right)-\min \left(\begin{array}{c}
\mathrm{P}_{\mathrm{LD}} \\
\mathrm{P}_{\mathrm{LN}}
\end{array}\right)}{\mathrm{P}_{\mathrm{MR}}}[\mathrm{kg}]
$$

The second condition is related to the capacity. The total mass of the batteries with sufficient capacity may be calculated according to Equation (25):

$$
\mathrm{M}_{\mathrm{EBS} . \mathrm{B}, 2}=\frac{\left(\mathrm{P}_{\mathrm{equ}, 0}+\max \left(\begin{array}{c}
\mathrm{P}_{\mathrm{TCS}, \mathrm{LD}} \\
\mathrm{P}_{\mathrm{TCS}, \mathrm{LN}}
\end{array}\right)\right) \cdot 24}{\mathrm{e}_{\mathrm{s}} \cdot \eta_{\mathrm{dis}} \cdot \mathrm{DOD}}[\mathrm{kg}]
$$

Finally, the mass of EBS batteries $\mathrm{M}_{\mathrm{EBS} . \mathrm{Bis}}$ is to be selected as the larger value of these two results according to Equation (26):

$$
M_{\text {EBS. } B}=\max \left\{\begin{array}{l}
M_{E B S . B, 1} \\
M_{E B S . B, 2}
\end{array}\right.
$$

In case of the RFCs, meeting the capacity condition requires proper sizing of the volume of reactant storage tanks and the mass of the reactants themselves. The minimum output power of the RFC-based EBS is to be guaranteed by ensuring adequate flow rate of the reactants. Sizing the RFC-EBS was accomplished the same way as in the case of RFC-ESS.

\section{Energy Storage Temperature Control System}

All energy storage devices produce waste heat during their operations. The problem is most significant for the RFCs due to the relatively low energy efficiency of the fuel cells. In the lunar surface environment, waste heat generation by a massive ESS becomes a serious problem due to relatively low radiative heat transfer to outer space, extremely low thermal conductivity of the lunar regolith and the absence of a proper heat sink [33]. In this situation, all the ESS components must be protected from additional heat gains caused by solar radiation and equipped with additional solutions enabling efficient dissipation of waste heat. Protection from the solar radiation is realized by the application of multilayer-insulation (MLI), while the waste heat is removed by a passive system consisting of cold plates and heat pipes that transfer the heat to the radiator. We conducted our calculations of ESS-TCS mass on the scaling coefficients method presented in detail in [27]. Temperatures of the lunar surface necessary to perform the calculations for different selenographic latitudes are presented in Table 4. 


\section{Results and Discussion}

\subsection{Baseline Configuration}

The baseline configuration of the studied lunar base often served as a reference case for our analysis. The details of this configuration are gathered in Table 9 as a supplement to the information provided in Section 2.2.

Table 9. Parameters of the baseline configuration.

\begin{tabular}{ccc}
\hline Parameter & Symbol & Value \\
\hline selenographic latitude & $\phi_{\text {sel }}\left({ }^{\circ}\right)$ & 0 \\
Solar radiation factor & $\mathrm{f}_{\mathrm{SR}}(\%)$ & 100 \\
Power adjustment coefficient & $\mathrm{C}_{\mathrm{PA}}(-)$ & 0 \\
Power increase coefficient & $\mathrm{C}_{\mathrm{PI}}(-)$ & 0 \\
Sun tracking coefficient & $\mathrm{C}_{\mathrm{ST}}(\%)$ & 61.9 \\
Solar array structure specific & $\rho_{\mathrm{PVS}}\left(\mathrm{kg} / \mathrm{m}^{2}\right)$ & 0.55 \\
mass & & \\
\hline
\end{tabular}

Table 10 presents a detailed power system breakdown for the baseline configuration. One may easily observe, that for the baseline configuration, any power system utilizing nuclear reactor exhibits a considerable mass advantage over PV-only solutions. The lowest mass $2220 \mathrm{~kg}$ is achieved by a hybrid (NFR+PV) system using Li-S batteries. Although its batteries $(335 \mathrm{~kg}$ ) weigh somewhat more than the energy storage of NFR+PV+RFC system $(296 \mathrm{~kg})$, high energy efficiency Li-S batteries produce much less waste heat than the fuel cells, which largely saves its TCS mass. The great majority of any PV-based system mass $(70-95 \%)$ is produced by its high-capacity ESS. The RFC-based energy storage is clearly the least massive ESS, but in comparison with Li-S batteries most of the RFC's mass advantage is lost due to its need for a much larger TCS. For a relatively low-capacity energy buffer, Li-S batteries with their TCS present a considerable mass advantage over the RFC and its TCS. When high-capacity ESS is discussed, the RFC becomes more advantageous, even despite its relatively massive TCS. Relatively low specific energy of Li-ion batteries makes this ESS/EBS solution definitely the least favorable option when the total system mass is considered.

\subsection{Location}

In order to determine the impact of the lunar base global location on its power system mass, we performed the sizing procedure for all nine power system architectures for the four different selenographic latitudes. Total masses of each system at different latitudes are given in Table 11.

In general, our results demonstrate, that the selenographic latitude has little impact on the total mass of a lunar base power system. In most cases, the relative difference between the results for a specified power system are about $1 \%$ or less, as demonstrated in Table 12 .

The only significant variations in $\mathrm{M}_{\mathrm{tot}}$ with latitude are observed for the three power systems that use RFCs for energy storage or buffering. In every case however, an increase in a system mass is noticed between $0^{\circ}$ and $30^{\circ}$ latitude. After that, $\mathrm{M}_{\text {tot }}$ decreases with growing latitude. We are convinced that this trend is to be explained by the interaction between the TCS radiator and the sunlight incident on it. For any solid there exists a solar elevation angle that results in a maximum instantaneous illumination of that solid. For a cube this angle is $45^{\circ}$, as the function $\sin \theta+\cos \theta$ yields the maximum possible value at that angle. Different latitudes give different values of daily mean solar elevation angle, which is one of the factors influencing the radiator mass [27]. During the lunar day solar heat gains received by the radiator increase its temperature and negatively affect its performance. In practice, the problem is complicated by latitude-related lunar surface diurnal temperature changes as seen in Table 4 . It may be observed that relative system mass differences are particularly high for RFC-based systems. This energy storage solution has relatively low energy efficiency and, as a result, relatively high waste heat emission. The RFCS that require particularly large radiators for their waste heat dissipation seem to be highly susceptible to the described effect. 
Table 10. Baseline configuration power systems breakdown.

\begin{tabular}{|c|c|c|c|c|c|c|c|}
\hline \multirow[b]{2}{*}{$\begin{array}{l}\text { Power System } \\
\text { Architecture }\end{array}$} & \multicolumn{7}{|c|}{ Power System Components Mass (kg) } \\
\hline & Solar Array $\mathbf{M}_{\mathrm{PVA}}$ & $\begin{array}{c}\text { Reactor } \\
\text { Assembly } \mathbf{M}_{\mathrm{NFR}}\end{array}$ & Batteries $\mathbf{M}_{\mathrm{ESS} . \mathrm{B}}$ & $\begin{array}{l}\text { Regenerative Fuel } \\
\text { Cells } M_{\text {ESS.RFC }}\end{array}$ & $\begin{array}{c}\text { Temperature Control } \\
\text { System } \mathrm{M}_{\mathrm{TCS}}\end{array}$ & $\begin{array}{c}\text { Balance of } \\
\text { System } M_{B S}\end{array}$ & Total Mass $\mathbf{M}_{\text {tot }}$ \\
\hline PV+Li-ion & 246 & 0 & 17,526 & 0 & 630 & 10 & 18,412 \\
\hline $\mathrm{PV}+\mathrm{Li}-\mathrm{S}$ & 246 & 0 & 5668 & 0 & 262 & 10 & 6186 \\
\hline $\mathrm{PV}+\mathrm{RFC}$ & 336 & 0 & 0 & 4236 & 1500 & 15 & 6087 \\
\hline NFR+Li-ion & 0 & 1545 & 1026 & 0 & 93 & 338 & 3002 \\
\hline NFR+Li-S & 0 & 1545 & 334 & 0 & 64 & 338 & 2282 \\
\hline NFR+RFC & 0 & 1545 & 0 & 296 & 698 & 338 & 2877 \\
\hline $\mathrm{NFR}+\mathrm{PV}+\mathrm{Li}-\mathrm{S}$ & 130 & 1418 & 335 & 0 & 64 & 271 & 2220 \\
\hline $\mathrm{NFR}+\mathrm{PV}+\mathrm{RFC}$ & 130 & 1418 & 0 & 296 & 698 & 271 & 2814 \\
\hline
\end{tabular}


Table 11. Total mass of a power system as a function of its architecture and selenographic latitude.

\begin{tabular}{ccccc}
\hline \multirow{2}{*}{ Power System Architecture } & \multicolumn{4}{c}{ Total System Mass $\mathbf{M}_{\text {tot }}(\mathbf{k g})$} \\
\hline PV+Li-ion & $\mathbf{0}^{\circ}$ & $\mathbf{3 0}^{\circ}$ & $\mathbf{6 0}^{\circ}$ & $\mathbf{8 9}^{\circ}$ \\
PV+Li-S & 18,412 & 18,417 & 18,386 & 18,372 \\
PV+RFC & 6186 & 6191 & 6160 & 6146 \\
NFR+Li-ion & 6087 & 6247 & 5464 & 5152 \\
NFR+Li-S & 3002 & 3007 & 2982 & 2971 \\
NFR+ RFC & 2282 & 2287 & 2262 & 2252 \\
NFR+PV+Li-ion & 2877 & 2953 & 2582 & 2445 \\
NFR+PV+Li-S & 2940 & 2944 & 2917 & 2904 \\
NFR+PV+RFC & 2220 & 2224 & 2197 & 2184 \\
& 2814 & 2890 & 2516 & 2377 \\
\hline
\end{tabular}

Table 12. Maximum relative differences in the total system mass based on the data for $0^{\circ}, 30^{\circ}, 60^{\circ}$ and $89^{\circ}$ selenographic latitude.

\begin{tabular}{cc}
\hline Power system Architecture & Max. Relative System Mass Difference (\%) \\
\hline PV+Li-ion & 0.25 \\
PV+Li-S & 0.73 \\
PV+RFC & 17.53 \\
NFR+Li-ion & 1.17 \\
NFR+Li-S & 1.54 \\
NFR+ RFC & 17.23 \\
NFR+PV+Li-ion & 1.34 \\
NFR+PV+Li-S & 1.78 \\
NFR+PV+RFC & 17.75 \\
\hline
\end{tabular}

\subsection{Solar Radiation Factor}

The study on the influence of varying solar illumination conditions on the power system total mass was based on the analysis of a modified baseline configuration of the facility. The analysis was performed for the eight different $f_{S R}$ values. All the calculations were performed for the lunar polar location $\left(89^{\circ}\right)$, where sites of those extreme illumination conditions may actually be found. For the fixed solar array mounts with $f_{S R}>100 \%$, we assumed a double solar array surface in order to enable utilization of the sunlight coming from the equatorial and from the polar direction. In that case, $\rho_{\text {PVS }}=0.85 \mathrm{~kg} / \mathrm{m}^{2}$ for double-sided fixed mount was assumed. Parameters for the Solar radiation factor study are presented in Table 13.

Table 13. Parameters for the Solar radiation factor study.

\begin{tabular}{ccc}
\hline Parameter & Symbol & Value/Range \\
\hline selenographic latitude & $\phi_{\text {sel }}\left({ }^{\circ}\right)$ & 89 \\
Solar radiation factor & $\mathrm{f}_{\mathrm{SR}}(\%)$ & $25 \%, 50 \%, 75 \%, 100 \%, 125 \%$, \\
Power adjustment coefficient & $\mathrm{C}_{\mathrm{PA}}(-)$ & $150 \%, 175 \%, 195 \%$ \\
Power increase coefficient & $\mathrm{C}_{\mathrm{PI}}(-)$ & 0 \\
Sun tracking coefficient & $\mathrm{C}_{\mathrm{ST}}(\%)$ & 0 \\
Solar array structure specific mass & $\rho_{\mathrm{PVS}}\left(\mathrm{kg} / \mathrm{m}^{2}\right)$ & $61.91 \%$ \\
\hline
\end{tabular}

The results for nuclear and hybrid power systems are presented in Table 14.

As expected, all three nuclear-only (NFR) power systems were completely unaffected by varying solar illumination conditions. The three hybrid power systems (NFR+PV) experienced slight increase in their masses when enhanced PV arrays were applied for $\mathrm{f}_{\mathrm{SR}}>100 \%$. Although the hybrid systems are slightly more massive than NFR systems, utilizing solar radiation during prolonged lunar days saves the nuclear fuel and prolongs the reactor's operational time. Despite their higher weight and increased system 
complexity, hybrid power systems have the potential to be more beneficial in the long term, when $>10$ years operation periods are analyzed. A wide range of $\mathrm{f}_{\mathrm{SR}}$ resulted in the obtainment of significant differences in lunar day and night durations, as depicted in Figure 2.

Table 14. Total mass of the nuclear and hybrid power systems for different solar radiation coefficients $\mathrm{f}_{\mathrm{SR}}$.

\begin{tabular}{ccc}
\hline Power System Architecture & $\begin{array}{c}\text { Power System Total Mass (kg) } \\
\mathbf{f}_{\mathbf{S R}} \leq \mathbf{1 0 0} \mathbf{0}\end{array}$ & $\begin{array}{c}\text { Power System Total Mass (kg) } \\
\mathbf{f}_{\mathbf{S R}}>\mathbf{1 0 0} \%\end{array}$ \\
\hline NFR+Li-ion & 2915.39 & 2915.39 \\
NFR+Li-S & 2195.47 & 2195.47 \\
NFR+ RFC & 2388.56 & 2388.56 \\
NFR+PV+Li-ion & 2904.12 & 3014.56 \\
NFR+PV+Li-S & 2184.16 & 2294.60 \\
NFR+PV+RFC & 2376.51 & 2486.95 \\
\hline
\end{tabular}

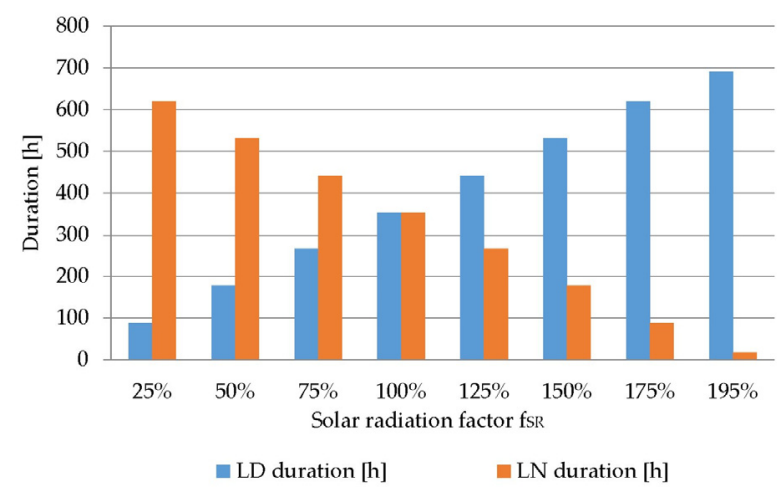

Figure 2. Variations of the lunar day and night durations for different $\mathrm{f}_{\mathrm{SR}}$ values.

Unlike NFR or hybrid solutions, the PV power system mass exhibits strong dependence on the site solar illumination conditions. The results of this analysis conducted for PV-based power systems are presented in Figure 3.

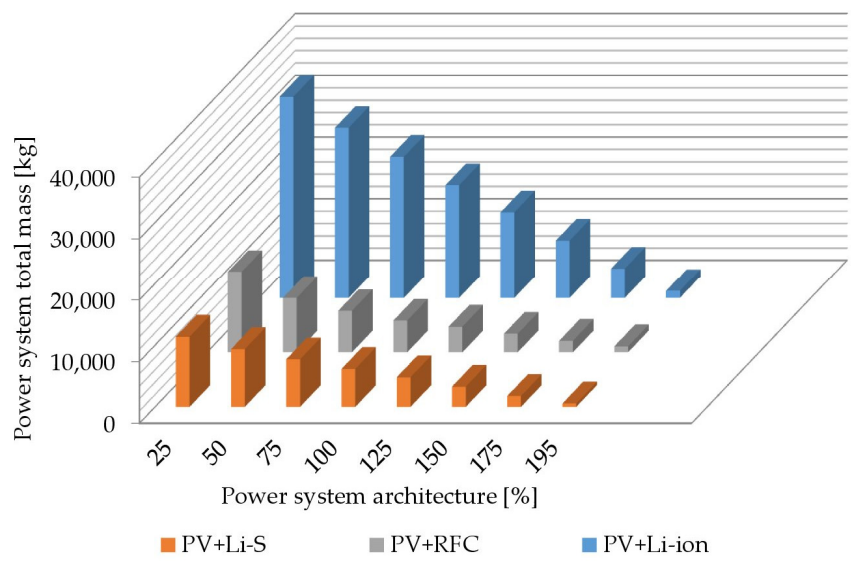

Figure 3. Total masses of photovoltaic (PV)-based power systems at varying solar illumination.

The changes of $\mathrm{f}_{\mathrm{SR}}$ have a double effect on PV power systems. Firstly, it changes the lunar day duration-a period used to produce and store electric energy to support nighttime operations of the base. In this way, the $\mathrm{f}_{\mathrm{SR}}$ influences the solar array power output and, as a consequence, its mass. Secondly, $\mathrm{f}_{\mathrm{SR}}$ influences lunar night-time duration-a variable crucial for sizing the base ESS capacity and so its mass.

Comparing the results from Table 14 and Figure 3, one may conclude that, according to our assumptions, an $\mathrm{f}_{\mathrm{SR}}$ value of about $150 \%$ is necessary if the total mass of a PVbased power system is to become comparable with nuclear or hybrid solutions. The first 
PV system to reach that mass advantage is the one combined with RFC energy storage. With increasing solar energy availability and decreasing the required ESS capacity, at $\mathrm{f}_{\mathrm{SR}}=175 \%$, the PV+Li-S system becomes lighter than PV+RFC and any NFR or hybrid solution. The PV+Li-ion system requires as extreme illumination as $\mathrm{f}_{\mathrm{SR}}=195 \%$ to outmatch the NFR or hybrid systems.

\subsection{Power Increase Coefficient}

In this paragraph, the impact of the lunar base power load on the total mass of its power system will be discussed. We performed power systems analysis for the three values of the power increase coefficient $C_{\mathrm{PI}}$. A brief summary of the studied configurations is to be seen in Table 15.

Table 15. Parameters for the base power increase coefficient study.

\begin{tabular}{ccc}
\hline Parameter & Symbol & Value/Range \\
\hline Selenographic latitude & $\phi_{\text {sel }}\left({ }^{\circ}\right)$ & 0 \\
Solar radiation factor & $\mathrm{f}_{\mathrm{SR}}(\%)$ & $100 \%$ \\
Power adjustment coefficient & $\mathrm{C}_{\mathrm{PA}}(-)$ & 0 \\
Power increase coefficient & $\mathrm{C}_{\mathrm{PI}}(-)$ & $0,2,4$ \\
Sun tracking coefficient & $\mathrm{C}_{\mathrm{ST}}(\%)$ & $61.91 \%$ \\
Solar array structure specific mass & $\rho_{\mathrm{PVS}}\left(\mathrm{kg} / \mathrm{m}^{2}\right)$ & 0.55 \\
\hline
\end{tabular}

We named the three subsequent cases as the low, moderate and high power modes, respectively. The lunar base power loads for these three power modes are presented in Table 16.

Table 16. The lunar base power loads at various power modes.

\begin{tabular}{cccc}
\hline $\begin{array}{c}\text { Power Increase } \\
\text { Coefficient } \mathbf{C}_{\mathbf{P I}}\end{array}$ & Power Mode & Lunar Day $\mathbf{P}_{\mathbf{L D}}$ & Lunar Night $\mathbf{P}_{\mathbf{L N}}$ \\
\hline 0 & low & 8977 & 7832 \\
2 & moderate & 28,977 & 27,832 \\
4 & high & 48,977 & 47,832 \\
\hline
\end{tabular}

For a specified power mode, the base equipment loads are identical during LD and LN. The differences observed between $\mathrm{P}_{\mathrm{LD}}$ and $\mathrm{P}_{\mathrm{LN}}$ are caused by different power demands of the base active TCS which is subjected to different cooling loads during lunar days and nights. Power system total masses for each studied architecture at the three power modes are presented in Figure 4.

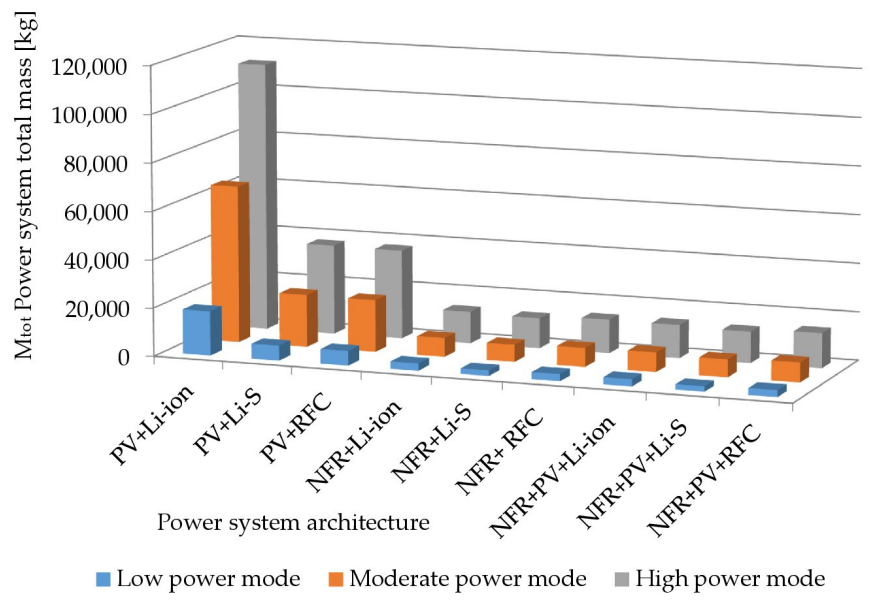

Figure 4. Total mass of the power systems for different power modes. 
One may observe that, for every power system architecture, the relative differences in the total system mass for the subsequent power modes are very similar to the ratios of the total power demands for subsequent power modes. In other words, within the assumed parameter range, the relative changes in power system masses are approximately proportional to the relative changes in the total power demand of the base. It also means, that the absolute mass differences increase with power demand. For example, in low power mode, selecting the NFR+Li-S power system instead of the PV+Li-ion system saves about 16 metric tons of payload, but for the high power mode the saving grows to more than 99 metric tons. This shows that the proper selection of a lunar base power system is one of the key factors determining the feasibility and cost of the endeavor. A previously presented pattern is again to be observed here-for high-capacity energy storage, RFCs present a net mass advantage, but in a relatively low-capacity energy buffering system, Li-S's are a better choice if the total mass is considered. The reason for this is a non-linear scaling of RFCs, which exhibit low specific energy over low power output and at low storage capacities. This phenomenon was previously reported and elaborated upon by [27] and [28] This section of our analysis may be concluded with a statement, that unless extraordinarily beneficial site illumination is available, the application of a nuclear power source for a permanently manned lunar base seems to be unavoidable. For a great majority of the lunar surface, two power systems are recommended: NFR+Li-S and NFR+PV+Li-S. The former offers simplicity and a slight mass advantage over the latter, the latter, however, may have extended lifespan and may be found to be more mass and cost effective after more than 10 years of operation.

\subsection{Power Adjustment Coefficient}

The influence of assumed power load management strategies on the lunar base power system mass were studied by calculating the mass for each power system architecture for four different values of power adjustment coefficients. Most of the baseline power demand consists of the minimum base equipment power loads Pequ.0; relatively little power load may be rescheduled from LN to LD in that particular configuration. We therefore decided to use moderate power mode (see: Section 3.4) as a reference value for this part of our analysis. The summary of the studied configurations is presented in Table 17.

Table 17. Parameters for the base power adjustment coefficient study.

\begin{tabular}{ccc}
\hline Parameter & Symbol & Value/Range \\
\hline Selenographic latitude & $\phi_{\text {sel }}\left({ }^{\circ}\right)$ & 0 \\
Solar radiation factor & $\mathrm{f}_{\mathrm{SR}}(\%)$ & $100 \%$ \\
Power adjustment coefficient & $\mathrm{C}_{\mathrm{PA}}(-)$ & $0,0.33,0.66,1$ \\
Power increase coefficient & $\mathrm{C}_{\mathrm{PI}}(-)$ & 2 \\
Sun tracking coefficient & $\mathrm{C}_{\mathrm{ST}}(\%)$ & $61.91 \%$ \\
Solar array structure specific mass & $\rho_{\mathrm{PVS}}\left(\mathrm{kg} / \mathrm{m}^{2}\right)$ & 0.55 \\
\hline
\end{tabular}

The power adjustment coefficient exerts a significant influence on the base power load distribution in a lunar cycle, as shown in Table 17. Table 18 presents the lunar day and night base power loads for each $\mathrm{C}_{\mathrm{PI}}$ value studied here.

Table 18. The lunar base power loads for various power management strategies.

\begin{tabular}{ccc}
\hline \multirow{2}{*}{ Power Adjustment Coefficient $\mathbf{C}_{\mathbf{P A}}$} & \multicolumn{2}{c}{ Total Power Demand (W) } \\
& Lunar Day $\mathbf{P}_{\mathbf{L D}}$ & Lunar Night $\mathbf{P}_{\mathbf{L N}}$ \\
\hline 0 & 28,977 & 27,832 \\
0.33 & 35,804 & 21,005 \\
0.66 & 42,630 & 14,178 \\
1 & 49,663 & 7144 \\
\hline
\end{tabular}

The results of the calculations conducted are presented in Figure 5. 


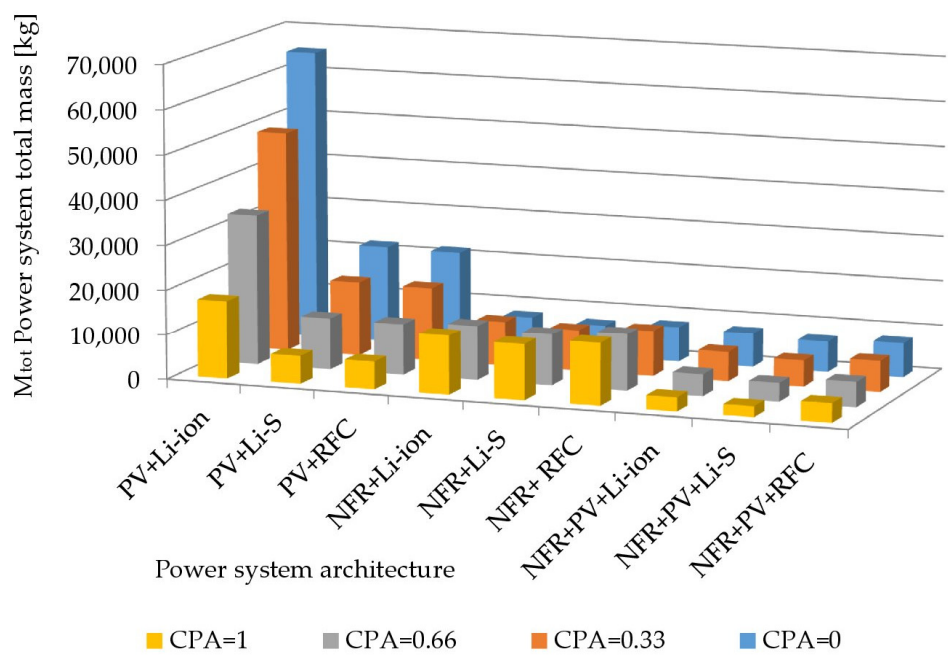

Figure 5. Total mass of the power systems for different power management strategies.

It may be observed that scheduling power-demanding lunar base operations for lunar days while simultaneously minimizing lunar night-time power loads may result in a considerable reduction in a PV-based power system's mass. This strategy enables direct use of relatively high specific power solar arrays, and at the same time reduces the amount of energy to be stored in ESS, and as a consequence minimizing system mass. This practice is not so beneficial for purely nuclear power systems. NFRs are sized according to the larger of $\mathrm{P}_{\mathrm{LD}}$ and $\mathrm{P}_{\mathrm{LN}}$ power loads, so their efficient use promotes balanced power management strategies. Scheduling as many power loads for lunar days is also recommended for hybrid power systems, as it leads to decrease in the reactor's mass. Despite the fact that adjusting the base power loads for intensive lunar day operations presents a huge advantage for lunar PV systems, the most effective, from a gravimetric point of view, is to use a hybrid power system, most preferably one equipped with a Li-S energy buffer, should the technology become eventually reliable and available.

\subsection{Sun Tracking Coefficient and PV Array Structure}

In this section of our analysis, two interrelated solar array parameters were studied. In order to assess the effect of using a solar array fixed mount and single-axis solar tracker on a lunar base power system's mass, we performed the calculations for these two array structure types at two lunar locations, with different solar illumination conditions. Table 19 presents a total of four sets of parameters used to calculate total power system mass for PV and hybrid solutions, as the nuclear reactor-only architectures remain unaffected by varying solar array parameters.

Table 19. Parameters for the study on the applied solar array structure type.

\begin{tabular}{|c|c|c|c|c|c|}
\hline \multirow{2}{*}{ Parameter } & \multirow{2}{*}{ Symbol } & \multicolumn{4}{|c|}{ Value } \\
\hline & & EF & ET & PF & PT \\
\hline Selenographic latitude & $\phi_{\text {sel }}\left({ }^{\circ}\right)$ & 0 & 0 & 89 & 89 \\
\hline Solar radiation factor & $\mathrm{f}_{\mathrm{SR}}(\%)$ & $100 \%$ & $100 \%$ & $175 \%$ & $175 \%$ \\
\hline Power adjustment coefficient & $\mathrm{C}_{\mathrm{PA}}(-)$ & 0 & 0 & 0 & 0 \\
\hline Power increase coefficient & $\mathrm{C}_{\mathrm{PI}}(-)$ & 0 & 0 & 0 & \\
\hline Sun tracking coefficient & $\mathrm{C}_{\mathrm{ST}}(\%)$ & $61.91 \%$ & $99.99 \%$ & $61.91 \%$ & $99.99 \%$ \\
\hline Solar array structure specific mass & $\rho_{\text {PVS }}\left(\mathrm{kg} / \mathrm{m}^{2}\right)$ & 0.55 & 2.5 & 0.85 & 2.5 \\
\hline Solar array surface area & - & single & single & double & single \\
\hline
\end{tabular}

Where: EF-equatorial location with fixed array mount, ET—equatorial location with solar tracker, PF-polar location with fixed array mount, PT-polar location with solar tracker.

The results of total mass calculations for the six system architectures are presented in Figure 6. 


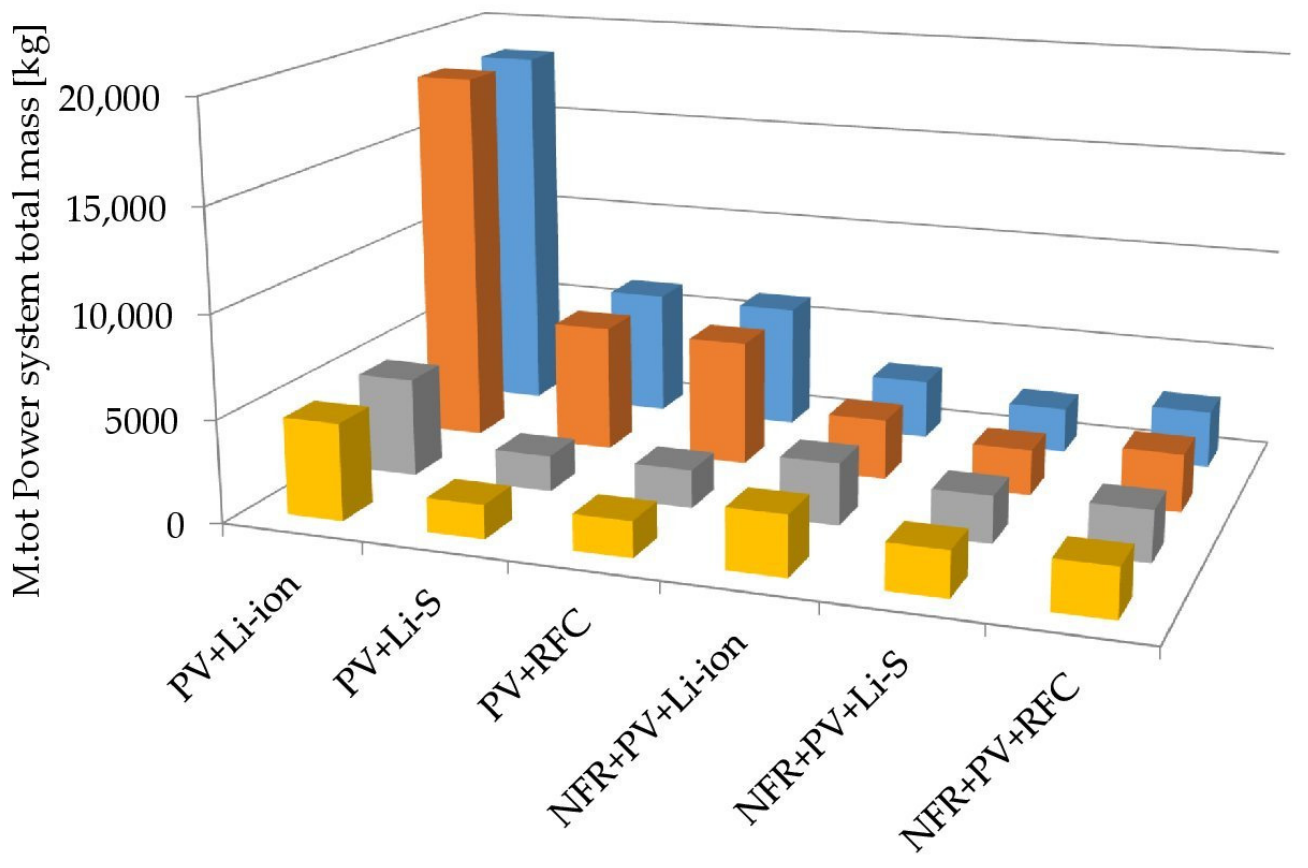

Power system architecture

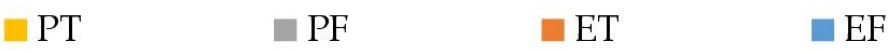

Figure 6. Total mass of the power systems with different solar array structures for specified site illumination.

It may be easily observed that, in case of the studied lunar equatorial conditions, using a solar tracking array resulted in a net increase in total mass for all power system architectures. In order to provide more detailed explanation, the power system mass breakdown for a selected architecture is presented in Table 20.

Table 20. PV+Li-S power system solar array mass breakdown.

\begin{tabular}{ccccc}
\hline \multirow{2}{*}{ Power System Component } & EF & ET & PF & PT \\
\hline PV array & 140.6 & 87 & 161.9 & 50.1 \\
array structure & 48.6 & 136.9 & 43.3 & 78.8 \\
wiring & 1.8 & 1.6 & 0.8 & 0.7 \\
breaker box & 8.4 & 4.9 & 3.4 & 2 \\
total M & 199.4 & 230.4 & 209.4 & 131.6 \\
\hline
\end{tabular}

Although the data presented in Table 20 refer to a specified system, the pattern visible is common for all power systems studied in this part of our analysis. Mass of the photovoltaic array system $\mathrm{M}_{\mathrm{PV}}$ produces the only mass differences for a specified power system architecture-masses of energy storages, thermal control and nuclear reactor assemblies remain unchanged for all four studied cases.

The solar illumination conditions at the equatorial site were found to be insufficient to reduce the solar array mass to the extent that they compensate for the higher areal density of a solar tracker with respect to the fixed mount. The differences in the balance of system mass are relatively small and do not have a significant impact on the total system mass. At the polar "peak of eternal light", however, two factors influence the net result, which is more advantageous for the solar tracking array. The first is much greater illumination, which enables significant reduction in the solar array surface. Note the fact that at the polar location we assumed the use of a double-sided mount and twice the solar panel 
area, compared with the non-polar locations, so the almost $162 \mathrm{~kg}$ polar array is actually $281 \mathrm{~kg}$, to be compared with a single equatorial array weighing $140.6 \mathrm{~kg}$. The second factor is the reduction in the relative difference in the areal density of array structures. At the equatorial site it was $0.55 \mathrm{~kg} / \mathrm{m}^{2}$ vs $2.5 \mathrm{~kg} / \mathrm{m}^{2}$, while at the lunar pole it was $0.85 \mathrm{~kg} / \mathrm{m}^{2}$ vs $2.5 \mathrm{~kg} / \mathrm{m}^{2}$, which makes the polar array structure mass difference easier to compensate. It is to be observed, however, that the sites with that offer extraordinarily advantageous illumination conditions constitute a minute fraction of the Moon's surface and, in general, according to our assumptions, using fixed mount solar arrays will be more effective than using solar trackers as long as the system mass is the main concern.

\subsection{Specified Case Studies}

Based on insight gathered in previous sections of this parametric study, three case studies were performed for a lunar base operating in three different lunar environmental conditions:

- $\quad$ Lunar Equatorial Scientific Base (LESB);

- Lunar Polar Scientific Base (LPSB) at a peak of eternal light;

- Lunar Crater In-Situ Resources Utilization Facility (LCIF) located in an interior of a crater of eternal darkness.

For these three cases, the most advantageous man-controlled parameters were applied along with environmental factors typical for each site. For these three cases, base power systems were sized and discussed. Key assumptions for the case studies are presented in Table 21.

Table 21. Assumptions for lunar base case studies.

\begin{tabular}{ccccc}
\hline Parameter & Symbol, Unit & LESB & LPSB & LCIF \\
\hline Selenographic latitude & $\phi_{\text {sel }}\left({ }^{\circ}\right)$ & 0 & 89 & 89 \\
Solar radiation factor & $\mathrm{f}_{\mathrm{SR}}(\%)$ & $98 \%$ & $175 \%$ & $0 \%$ \\
Power adjustment coefficient & $\mathrm{C}_{\mathrm{PA}}(-)$ & 1 & 1 & 0 \\
Power increase coefficient & $\mathrm{C}_{\mathrm{PI}}(-)$ & 1.5 & 1.5 & - \\
Sun tracking coefficient & $\mathrm{C}_{\mathrm{ST}}(\%)$ & $61.91 \%$ & $99.99 \%$ & - \\
Solar array structure & - & fixed mount & single axis solar tracker & - \\
Solar array structure specific mass & $\rho_{\mathrm{PVS}}\left(\mathrm{kg} / \mathrm{m}^{2}\right)$ & 395 & 179 & 40 \\
Lunar day max. surface temperature & $\mathrm{T}_{\mathrm{LD}}(\mathrm{K})$ & 95 & 60 & 40 \\
Lunar night min. surface temperature & $\mathrm{T}_{\mathrm{LN}}(\mathrm{K})$ & & \\
\hline
\end{tabular}

The results of these case study calculations are presented in Figure 7.

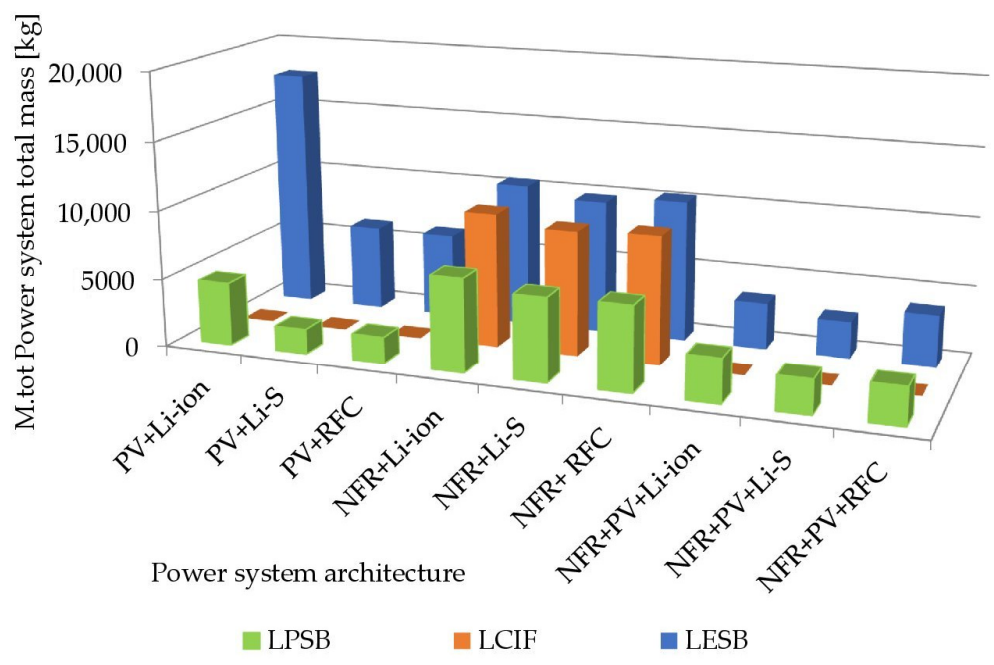

Figure 7. Total power system masses for the selected lunar base case studies. 


\subsubsection{Lunar Equatorial Scientific Base}

The power system total mass results for the Lunar Equatorial Scientific Base are in good agreement with our earlier conclusions, that for the great majority of the Moon's surface the most optimal, mass-saving lunar base power system must utilize a nuclear power source. In this particular case, an additional mass-optimizing strategy was to schedule all possible power-demanding activities for the lunar day. Applying this power management strategy enabled efficient harnessing of solar radiation to meet relatively high lunar daytime power demand. At the same time, the strategy reduced the lunar night-time nuclear reactor power load, enabling savings in the whole system mass. Owing to the fact the LESB hybrid power system does not require a massive, high-capacity ESS, the Li-S batteries turned out to be the best choice for a relatively low-capacity EBS. To sum up, for the studied LESB, a hybrid PV+NFR+Li-S power system is the best solution for masssaving policy. Weighing $2699 \mathrm{~kg}$, the system is evidently lighter than the remaining two hybrid solutions and considerably lighter than any solution from PV or NFR architectures.

\subsubsection{Lunar Polar Scientific Base}

Extraordinarily beneficial solar illumination at the peak of eternal light where LPSB is located cause the $\mathrm{PV}+\mathrm{Li}-\mathrm{S}$ power system to outmatch any other solution. Although this type of lunar base power system is, by definition, equipped with high-capacity ESS, and these promote RFCs rather than any batteries but the relatively short local lunar night requires much less energy storage capacity than it was in case of the LESB. As was observed in the previous paragraphs, Li-S batteries generate a slight mass saving over the RFCs when low-capacity energy storages are considered. If, however, the LPSB illumination conditions were unstable $[64,66]$, a slightly heavier PV+NFR+Li-S system would guarantee the minimum night-time stable power supply.

\subsubsection{Lunar Crater In-situ Resources Utilization Facility}

Since no sunlight ever reaches the bottom of the eternally shaded crater where the LCIF is located, the only feasible architecture to power the facility was based exclusively on nuclear energy. Again, the low-capacity energy buffer promoted the application of Li-S batteries; however, the low-temperature, zero-insolation crater environment required a smaller RFC radiator as was the case at the low-latitudinal regions of the Moon.

\section{Conclusions}

The extreme costs of launching cargo payloads from Earth to the lunar surface demand a future lunar base's subsystems to be rigorously optimized in terms of mass reduction. The most challenging issue for a lunar base power system design is the relatively long duration of a lunar night. During that period, high-specific power solar arrays are useless so the only contemporarily feasible option for night-time power supply for any lunar surface facility is to use either a nuclear fission reactor or a massive energy storage system (ESS). To meet the minimum power demand of the studied lunar base during a more than two-week-long lunar night, almost 16 metric tons of state-of-practice, space-rated lithium-ion batteries would be required.

The hypothetical application of not yet fully developed solutions like Lithium-Sulfur (Li-S) batteries or regenerative fuel cells (RFC) would reduce the ESS mass by a factor of three to four.

RFC-based high-capacity ESS may present up to an about 25\% mass advantage over Li-S-based solution, but this advantage decreases with required ESS capacity.

If the lunar base power system utilizes batteries, selenographic latitude has little effect on its total mass. This factor is significant only when RFCs are used for energy storage. While nuclear-only power systems remain unaffected by the site solar illumination conditions, a strong correlation exists between availability of solar radiation and the total mass of PV-only power systems. 
According to our assumptions, a lunar polar site illuminated more than $75 \%$ of a lunar cycle $\left(f_{S R} \geq 150 \%\right)$ enables a PV-only architecture to gain a mass advantage over nuclear power systems.

Above a specified minimum base power demand, the total power system mass scales almost linearly with its maximum power load. An efficient solution to minimize PV and hybrid power system mass would be to reduce lunar night-time power loads to theri minimum possible level and schedule all non-vital, powered base operations for lunar days. Contrarily, nuclear-only power systems exhibit the lowest total masses at a balanced, uniform base power demand.

In general, when the total system mass is considered, using optimally tilted, fixed mount solar arrays is more beneficial on the Moon's surface than utilizing single axis solar trackers. Only sufficiently illuminated lunar polar sites may promote the latter solution.

For the wide range of studied parameters, hybrid power systems that use solar arrays during lunar days and utilize a nuclear reactor during lunar nights were found to be the most reliable and the most advantageous solutions in terms of mass reduction.

Rare polar sites may exist with extraordinarily advantageous solar illumination conditions (peaks of eternal light) where using a mass-optimizing strategy photovoltaic system with a relatively low-capacity ESS outperforms a hybrid power system. In these conditions, achieving relatively minor mass saving demands that the longest periods of continuous darkness are limited just to several earth days.

Development of a reliable, high specific energy and high efficiency energy storage solution would enable increased feasibility of establishing the first lunar base, save on its launch mass and reduce the cost of the program.

Author Contributions: Conceptualization, M.K.; methodology, M.K.; formal analysis, M.K.; investigation, M.K.; resources, M.K. and M.M.; writing—original draft preparation, M.K. and M.M.; writing-review and editing, M.K. and M.M.; supervision, M.K. and M.M.; funding acquisition, M.M. All authors have read and agreed to the published version of the manuscript.

Funding: This research received no external funding.

Institutional Review Board Statement: Not applicable.

Informed Consent Statement: Not applicable.

Data Availability Statement: Not applicable.

Conflicts of Interest: The authors declare no conflict of interest.

\author{
Nomenclature \\ U.S. United States \\ ISRU in situ resources utilization \\ ESS energy storage system \\ PV photovoltaic \\ SPE solar proton event \\ GCR galactic cosmic rays \\ LC lunar cycle (synodic month) \\ Li-ion Lithium-ion \\ TCS temperature control system \\ RFC Regenerative Fuel Cells \\ Li-S Lithium-Sulphur \\ $\mathrm{P}_{\mathrm{MR}} \quad$ specific power (power-to-mass ratio, PMR) \\ NFR nuclear fission reactor \\ es specific energy (gravimetric energy density) \\ LAD lunar astronomical day \\ LAN lunar astronomical night \\ PEL peak of eternal light
}




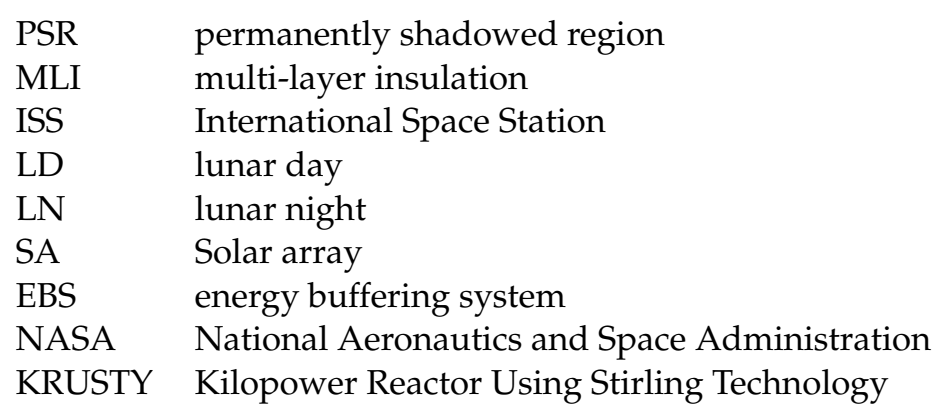

\section{References}

1. LUNEX-The National Security Archive. Available online: https://nsarchive2.gwu.edu/NSAEBB/NSAEBB479/docs/EBBMoon04.pdf (accessed on 25 November 2020).

2. Project HORIZON—The National Security Archive. Available online: https://nsarchive2.gwu.edu/NSAEBB/NSAEBB479/docs/ EBB-Moon01_sm.pdf (accessed on 25 November 2020).

3. The Soviet Manned Lunar Program. Available online: https://fas.org/spp/eprint/lindroos_moon1.htm (accessed on 25 November 2020).

4. Harvey, B. Soviet and Russian Lunar Exploration. In Springer Praxis Books; Praxis Publishing Ltd.: Chichester, UK, 2007; pp. 107-148. [CrossRef]

5. Space Exploration Initiative-NASA History Division. Available online: https://history.nasa.gov/sei.htm (accessed on 25 November 2020).

6. The Vision for Space Exploration—NASA. Available online: http://www.nasa.gov/pdf/55583main_vision_space_exploration2 .pdf (accessed on 25 November 2020).

7. Lunar Architecture-NASA. Available online: https://www.nasa.gov/pdf/140635main_ESAS_04.pdf (accessed on 25 November 2020).

8. NASA Exploration Systems Mission Directorate Lunar Surface Systems Concepts Study. Available online: https:/ / www.nasa.gov/ pdf/240373main_06-06-08-LSS\%20BAA\%20Compilation\%20of\%20briefings\%20teammb.pdf (accessed on 25 November 2020).

9. Chan, L.K.; Tsang, K.T.; Kong, B.; Zheng, Y.C. Lunar regolith thermal behavior revealed by Chang'E-1 microwave brightness temperature data. Earth Planet. Sci. Lett. 2010, 295, 287-291. [CrossRef]

10. Wang, Z.; Wu, Y.; Blewett, D.T.; Cloutis, E.A.; Zheng, Y.C.; Chen, J. Submicroscopic metallic iron in lunar soils estimated from the in situ spectra of the Chang'E-3 mission. Geophys. Res. Lett. 2017, 44, 3485-3492. [CrossRef]

11. China Daily—Chang'e 4 Finds Moon's far Side Colder than Expected during Night. Available online: https:/ /www.chinadaily. com.cn/a/201901/31/WS5c52b8eaa3106c65c34e797d.html (accessed on 4 July 2020).

12. Chang'e 5 Returns Home with Lunar Samples-Chinadaily.com. Available online: https://www.chinadaily.com.cn/a/202012/17/ WS5fda4ed3a31024ad0ba9c3d5.html (accessed on 20 December 2020).

13. Memorandum on the National Space Policy. The White House. Available online: https:/ / www.whitehouse.gov/presidentialactions/memorandum-national-space-policy/ (accessed on 23 July 2020).

14. NASA's Plan for Sustained Lunar Exploration and Development. Available online: https:/ /www.nasa.gov/sites/default/files/ atoms/files/a_sustained_lunar_presence_nspc_report4220final.pdf (accessed on 23 July 2020).

15. NASA Names New Moon Landing Program Artemis. Available online: https://www.space.com/nasa-names-moon-landingprogram-artemis.html (accessed on 23 July 2020).

16. The Artemis Plan-NASA. Available online: https://www.nasa.gov/sites/default/files/atoms/files/artemis_plan-20200921.pdf (accessed on 23 July 2020).

17. Evans, M.E.; Graham, L.D. A Flexible Lunar Architecture for Exploration (FLARE) supporting NASA's Artemis Program. Acta Astronaut. 2020, 177, 351-372. [CrossRef]

18. China Outlines Architecture for Future Crewed Moon Landings-sspacenews.com. Available online: https://spacenews.com/ china-outlines-architecture-for-future-crewed-moon-landings / (accessed on 8 September 2020).

19. China Unveils Ambitious Moon Mission Plans for 2024 and Beyond-Space.com. Available online: https:/ /www.space.com/ china-planning-future-moon-missions-change-7 (accessed on 8 September 2020).

20. The Washington Post-Another front in the Tensions between the U.S. and China: Space. Available online: https://www washingtonpost.com/technology /2019/07/26/another-front-tensions-between-us-china-space (accessed on 8 September 2020).

21. CNN-50 Years after US Moon Landing. China is Catching up in the Space Race. Available online: https:/ / edition.cnn.com/20 19/07/19/asia/china-apollo-us-space-race-intl-hnk/index.html (accessed on 8 September 2020).

22. The New Space Race-British Foreign Policy Group. Available online: https://bfpg.co.uk/2020/03/the-new-space-race/ (accessed on 10 September 2020).

23. Wharton. University of Pennsylvania-Why Big Business Is Making a Giant Leap into Space. Available online: https:// knowledge.wharton.upenn.edu/article/commercial-space-economy/ (accessed on 10 September 2020). 
24. National Geographic-The Future of Spaceflight-from Orbital Vacations to Humans on Mars. Available online: https://www. nationalgeographic.com/science/space/space-exploration/future-spaceflight/ (accessed on 10 September 2020).

25. Universetoday-How Space $X$ is Changing Starship to be Able to Land on the Moon. Available online: https://www. universetoday.com/146508/how-spacex-is-changing-starship-to-be-able-to-land-on-the-moon/ (accessed on 10 September 2020).

26. Hanford, A.J. Advanced Life Support Baseline Values and Assumptions Document; NASA/CR-2004-208941; Lockheed Martin Space Operations: Houston, TX, USA, 2004.

27. Colozza, A.J. Small Lunar Base Camp and In Situ Resource Utilization Oxygen Production Facility Power System Comparison; NASA Contractor Report, CR E-19754. 2020. Available online: https://ntrs.nasa.gov/citations/20200001622 (accessed on 10 January 2021).

28. Fraser, S.D. Theory and applications of cooling systems in lunar surface exploration. In Moon Prospective Energy and Material Resources; Badescu, V., Ed.; Springer: New York, NY, USA, 2012; p. 405. [CrossRef]

29. Federal Aviation Administration-The Annual Compendium of Commercial Space Transportation. 2018. Available online: https://www.faa.gov/about/office_org/headquarters_offices/ast/media/2018_ast_compendium.pdf (accessed on 10 December 2020).

30. NASA'S Management of Space Launch System: Program Costs and Contracts. Available online: https:/ / oig.nasa.gov/docs/IG20-012.pdf (accessed on 10 December 2020).

31. NASA Contractors Support Artemis Cost Estimate. Available online: https://www.space.com/nasa-contractors-support-artemiscost-estimate.html (accessed on 18 November 2020).

32. Zuniga, A.F.; Rasky, D.; Pittman, R.B.; Zapata, E.; Lepsch, R. Lunar COTS: An Economical and Sustainable Approach to Reaching Mars. In Proceedings of the AIAA SPACE 2015 Conference and Exposition, Pasadena, CA, USA, 31 August-2 September 2015. [CrossRef]

33. Kaczmarzyk, M.; Starakiewicz, A.; Waśniowski, A. Internal Heat Gains in a Lunar Base-A Contemporary Case Study. Energies 2020, 13, 3213. [CrossRef]

34. Benaroya, H. Lunar habitats: A brief overview of issues and concepts. Reach 2017, 7, 14-33. [CrossRef]

35. Herring, S.J.; Mackwell, S.; Pestak, C.; Hilser, K. Small Modular Fission Reactors for Space Applications. Nuclear and Emerging Technologies for Space; American Nuclear Society Topical Meeting: Richland, WA, USA, 2019; Available online: http:/ /anstd.ans. org/ (accessed on 12 October 2020).

36. McClure, P.R. Kilopower Project: The KRUSTY Fission Power Experiment and Potential Missions. Nucl. Technol. 2020, $206,1-12$. [CrossRef]

37. Landis, G.A.; Bailey, S.G. Photovoltaic power for a lunar base. Acta Astronaut. 1990, 22, 197-203. [CrossRef]

38. Space Solar Cells_Azur Space Solar Power GmbH. Available online: http://www.azurspace.com/index.php/en/products/ products-space/space-solar-cells (accessed on 12 October 2020).

39. Kaczmarzyk, M.; Gawroński, M.; Piątkowski, G. Global database of direct solar radiation at the Moon's surface for lunar engineering purposes. E3S Web Conf. 2018, 49, 00053. [CrossRef]

40. Girish, T.E.; Aranya, S. Moon's Radiation Environment and Expected Performance of Solar Cells during Future Lunar Missions. 2010. Available online: https:/ / arxiv.org/abs/1012.0717 (accessed on 12 October 2020).

41. Yu, B.; Zhang, T.; Liu, T.; Yao, L. Reliability Evaluation and In-Orbit Residual Life Prediction for Satellite Lithium-Ion Batteries. Math. Probl. Eng. 2018, 5, 1-12. [CrossRef]

42. NASA. Technology Taxonomy. Available online: https://www.nasa.gov/offices/oct/taxonomy/index.html (accessed on 12 October 2020).

43. Bland, J.B.; Abramson, M.; Arnold, R. Powering a Moon Base through the Lunar Night. The Space Review. 2015. Available online: https:/ / www.thespacereview.com/article/2882/1 (accessed on 9 October 2020).

44. Garcia, C.P.; Chang, B.J.; Johnson, D.W.; Bents, D.J.; Scullin, V.J.; Jakupca, I.J. Round trip energy efficiency of NASA Glenn regenerative fuel cell system. In NASA Technical Memorandum 2006; TM-2006-214054; NASA: Washington, DC, USA, 2006.

45. Fotouhi, A.; Auger, D.J.; O’Neill, L.; Cleaver, T.; Walus, S. Lithium-Sulfur Battery Technology Readiness and Applications-A Review. Energies 2017, 10, 1937. [CrossRef]

46. Zhu, K.; Wang, C.; Chi, Z.; Ke, F.; Yang, Y.; Wang, A.; Wang, W.; Miao, L. How Far Away Are Lithium-Sulfur Batteries From Commercialization? Front. Energy Res. 2019, 15. [CrossRef]

47. Maurer, C.; Commerell, W.; Hintennach, A.; Jossen, A. Capacity Recovery Effect in Lithium Sulfur Batteries for Electric Vehicles. World Electr. Veh. J. 2018, 9, 34. [CrossRef]

48. Siczek, K.; Siczek, K.; Piersa, P.; Adrian, Ł.; Szufa, S.; Obraniak, A.; Kubiak, P.; Zakrzewicz, W.; Bogusławski, G. The Comparative Study on the Li-S and Li-Ion Batteries Cooperating with the Photovoltaic Array. Energies 2020, 13, 5109. [CrossRef]

49. Steenstra, E.S.; Westrenen, W. Sulfides in the Moon. In Encyclopedia of Lunar Science; Cudnik, B., Ed.; Springer: Cham, Switzerland, 2017; pp. 107-148. [CrossRef]

50. Wang, Z.; Dong, Y.; Li, H.; Zhao, Z.; Wu, H.B.; Hao, C.; Liu, C.; Qiu, J.; Wen, X. Lou Enhancing lithium-sulphur battery performance by strongly binding the discharge products on amino-functionalized reduced graphene oxide. Nat. Commun. 2014, 5, 5002. [CrossRef] 
51. Simonsen, L.C.; De Barro, M.J.; Farmer, J.T.; Thomas, C.C. Conceptual design of a lunar base thermal control system. In Proceedings of the NASA Symposium on Lunar Bases and Space Activities in the 21st Century, Houston, TX, USA, 5-7 April 1988. LBS88-225.

52. Simonsen, L.J.; DeBarro, M.J.; Farmer, J.T. Conceptual Design of a Lunar Base Thermal Control System. Available online: https:/ /ntrs.nasa.gov/archive/nasa/casi.ntrs.nasa.gov/19930004815.pdf (accessed on 10 December 2019).

53. Friedlander, A.; Cole, K. Power Requirements for Lunar Base Scenarios. In Proceedings of the Second Conference on Lunar Bases and Space Activities of the 21st Century, Houston, TX, USA, 5-7 April 1988.

54. Waldron, R.D. Lunar Base Power Requirements. Options \& Growth. Available online: https://www.semanticscholar.org/ paper/Lunar-Base-Power-Requirements\%2C-Options-\%26-Growth-Waldron/b7e95959347a17941284d29a74c9ccf9c1717d8e (accessed on 20 January 2021).

55. Swanson, T.D.; Radermacher, R.; Costello, F.A.; Moore, J.S.; Mengers, D.R. low-temperature thermal control for a lunar base. SAE Tech. Pap. 1990, 901242. [CrossRef]

56. Sridhar, K.R.; Gottmann, M. Lunar base thermal control systems using heat pumps. Acta Astronaut. 1996, 39, 381-394. [CrossRef]

57. Cohen, M. Selected Precepts in Lunar Architecture. In Proceedings of the 53rd International Astronautical Congress, the World Space Congress-2002, Houston, TX, USA, 10 December 2002; IAC-02-Q.4.3.08. Available online: https://www.researchgate.net/ publication/228758914_Selected_precepts_in_lunar_architecture (accessed on 10 December 2019).

58. Khan, Z.; Vranis, A.; Zavoico, A.; Freid, S.; Manners, B. Power System Concepts for the Lunar Outpost: A Review of the Power Generation. Energy Storage. Power Management and Distribution (PMAD) System Requirements and Potential Technologies for Development of the Lunar Outpost. AIP Conf. Proc. 2006, 813, 1083-1092. [CrossRef]

59. Moon Fact Sheet-The NSSDCA-NASA. Available online: https://nssdc.gsfc.nasa.gov/planetary/factsheet/moonfact.html (accessed on 10 December 2019).

60. Horizon National Geographic Society. Available online: https://www.nationalgeographic.org/encyclopedia/horizon/ (accessed on 10 December 2019).

61. Christie, R.J.; Plachta, D.W.; Hasan, M.M. Transient Thermal Model and Analysis of the Lunar Surface and Regolith for Cryogenic Fluid Storage; NASA/TM-2008-215300; NASA: Cleveland, OH, USA, 2008; pp. 1-13.

62. Vasavada, A.R.; Bandfield, J.L.; Greenhagen, B.T.; Hayne, P.O. Lunar equatorial surface temperatures and regolith properties from the Diviner Lunar Radiometer Experiment. J. Geophys. Res. Atmos. 2012, 117, E12. [CrossRef]

63. Crost, A. Water on the Moon. I. Historical Overview. Astron. Rev. 2015, 6, 4-20. [CrossRef]

64. Bussey, D.B.J.; McGovern, J.A.; Spudis, P.D.; Neish, C.D.; Noda, H.; Ishihara, Y.; Sørensen, S.A. Illumination conditions of the south pole of the Moon derived using Kaguya topography. Icarus 2010, 208, 558-564. [CrossRef]

65. Bussey, D.B.J.; McGovern, J.A.; Greenhagen, B.T.; Paige, D.A.; Cahill, J.T.S.; Siegler, M.A.; Spudis, P.D. Global Catalogue of Lunar Permanently Shadowed Regions. In Proceedings of the European Planetary Science Congress 2012, Madrid, Spain, 23-28 September 2012; EPSC2012-756. Available online: http://meetings.copernicus.org/epsc2012 (accessed on 10 December 2019).

66. Speyerer, E.J.; Robinson, M.S. Persistently illuminated regions at the lunar poles: Ideal sites for future exploration. Icarus 2013, 222, 122-136. [CrossRef]

67. Wilhelm, B.; Mädler, J.H. Der Mond Nach Seinen Kosmischen und Individuellen Verhältissen Oder Allgemeine Vergleichende Selenographie; Simon Schropp and Co.: Berlin, Germany, 1837. (In Germany)

68. Sharpe, B.L.; Schrunk, D.G. Malapert Mountain Revisited. Adv. Space Res. 2003, 34, 832. [CrossRef]

69. McGovern, J.A.; Bussey, B.; Greenhagen, B.T.; Paige, D.A.; Cahill, J.; Spudis, P.D. Mapping and characterization of non-polar permanent shadows on the lunar surface. Icarus 2013, 223, 566-581. [CrossRef]

70. Li, S.; Lucey, P.G.; Milliken, R.E.; Hayne, P.O.; Fisher, E.; Williams., J.P.; Hurley, D.M.; Elphic, R.C. Direct evidence of surface exposed water ice in the lunar polar regions. Proc. Natl. Acad. Sci. USA 2018, 115, 8907-8912. [CrossRef]

71. Crotts, A. Water on the Moon. II. Origins \& Resources. Astron. Rev. 2012, 7, 36-47. [CrossRef]

72. Neish, C.D.; Bussey, D.B.J.; Spudis, P.; Marshall, W.; Thomson, B.J.; Patterson, G.W.; Carter, L.M. The nature of lunar volatiles as revealed by Mini-RF observations of the LCROSS impact site. J. Geophys. Res. Planets 2011, 116, E1. [CrossRef]

73. Kaczmarzyk, M.; Gawroński, M.; Piątkowski, G. Application of Finite Difference Method for determining lunar regolith diurnal temperature distribution. E3S Web Conf. 2018, 49, 00052. [CrossRef]

74. Schlick, C. An Inexpensive BRDF Model for Physically-based Rendering. Comput. Graphics Forum. 1994, 13, 233-246. [CrossRef]

75. Raut, H.K.; Ganesh, V.A.; Nair, A.S.; Ramakrishn, S. Anti-Reflective Coatings: A Critical. In-Depth Review. Energy Environ. Sci. 2011, 4, 3779-3804. [CrossRef]

76. Azur Space Solar Cell Assemblies. Available online: http://www.azurspace.com/images/0005906-01-00_DB_3G30A_8x8.pdf (accessed on 20 December 2020).

77. Duchek, M.E.; Colozza, A.J. Self-Deploying Tent Array for Mars Surface Solar Power. In Proceedings of the Conference AIAA 2018-1943, Spacecraft Structures Conference, Kissimmee, FL, USA, 8-12 January 2018. [CrossRef]

78. Eltech 11.120. Available online: https://eltech.net.pl/oferta/konstrukcje-fotowoltaiczne/konstrukcje-montazowe/montaz-nagruncie/ (accessed on 20 December 2020). (In Polish).

79. Lunar Surface Solar Array Structures SBIR.gov. Available online: https://www.sbir.gov/node/1836151 (accessed on 16 December 2020). 
80. Solar_Tracker-DSO-8PV. Available online: http://sklep.dotgreen.pl/wp-content/uploads/2016/02/Karta_kataloga_solar_ tracker-DSO-8PV.pdf (accessed on 16 December 2020).

81. STL36 Solar Tracker. Available online: http://m.solar-motors.com/gb/solar-tracker-stl36-single-axis-in-line-for-36-solar-panelswith-pillars-i564.shtml (accessed on 16 December 2020).

82. United States Nuclear Regulatory Commission: Information for Radiation Workers. Available online: https://www.nrc.gov/ about-nrc/radiation/health-effects/info.html\#dose (accessed on 16 December 2020).

83. Halpert, G.; Frank, H.; Surampudi, S. Batteries and Fuel Cells in Space. Electrochem. Soc. Interface 1999, 99-1388. Available online: https:/ / www.electrochem.org/dl/interface/fal/fal99/IF8-99-Pages25-30.pdf (accessed on 16 December 2020).

84. Mallon, K.; Assadian, F.; Fu, B. Analysis of On-Board Photovoltaics for a Battery Electric Bus and Their Impact on Battery Lifespan. Energies 2017, 10, 943. [CrossRef]

85. Narayan, S.R.; Valdez, T.I. High-Energy Portable Fuel Cell Power Sources. Electrochem. Soc. Interface 2008, 8, 40-45. Available online: https:/ / www.electrochem.org/dl/interface/wtr/wtr08/wtr08_p40-45.pdf (accessed on 16 December 2020). [CrossRef] 